\title{
Rain or snow: hydrologic processes, observations, prediction, and research needs
}

\author{
Adrian A. Harpold ${ }^{1}$, Michael L. Kaplan ${ }^{2}$, P. Zion Klos ${ }^{3}$, Timothy Link ${ }^{3}$, James P. McNamara ${ }^{4}$, Seshadri Rajagopal ${ }^{2}$, \\ Rina Schumer ${ }^{2}$, and Caitriana M. Steele ${ }^{5}$ \\ ${ }^{1}$ Department of Natural Resources and Environmental Science, University of Nevada, 1664 N. Virginia Street, \\ Reno, Nevada, USA \\ ${ }^{2}$ Division of Hydrologic Sciences, Desert Research Institute, 2215 Raggio Parkway, Reno, Nevada, USA \\ ${ }^{3}$ Department of Forest, Rangeland, and Fire Sciences, University of Idaho, 875 Perimeter Drive, Moscow, Idaho, USA \\ ${ }^{4}$ Department of Geosciences, Boise State University, 1910 University Dr., Boise, Idaho, USA \\ ${ }^{5}$ Jornada Experimental Range, New Mexico State University, Las Cruces, New Mexico, USA
}

Correspondence to: Adrian A. Harpold (aharpold@cabnr.unr.edu)

Received: 23 August 2016 - Published in Hydrol. Earth Syst. Sci. Discuss.: 31 August 2016

Revised: 6 December 2016 - Accepted: 8 December 2016 - Published: 2 January 2017

\begin{abstract}
The phase of precipitation when it reaches the ground is a first-order driver of hydrologic processes in a watershed. The presence of snow, rain, or mixed-phase precipitation affects the initial and boundary conditions that drive hydrological models. Despite their foundational importance to terrestrial hydrology, typical phase partitioning methods (PPMs) specify the phase based on near-surface air temperature only. Our review conveys the diversity of tools available for PPMs in hydrological modeling and the advancements needed to improve predictions in complex terrain with large spatiotemporal variations in precipitation phase. Initially, we review the processes and physics that control precipitation phase as relevant to hydrologists, focusing on the importance of processes occurring aloft. There is a wide range of options for field observations of precipitation phase, but there is a lack of a robust observation networks in complex terrain. New remote sensing observations have the potential to increase PPM fidelity, but generally require assumptions typical of other PPMs and field validation before they are operational. We review common PPMs and find that accuracy is generally increased at finer measurement intervals and by including humidity information. One important tool for PPM development is atmospheric modeling, which includes microphysical schemes that have not been effectively linked to hydrological models or validated against near-surface precipitation-phase observations. The review concludes by describing key research gaps and recommendations to im-
\end{abstract}

prove PPMs, including better incorporation of atmospheric information, improved validation datasets, and regional-scale gridded data products. Two key points emerge from this synthesis for the hydrologic community: (1) current PPMs are too simple to capture important processes and are not well validated for most locations, (2) lack of sophisticated PPMs increases the uncertainty in estimation of hydrological sensitivity to changes in precipitation phase at local to regional scales. The advancement of PPMs is a critical research frontier in hydrology that requires scientific cooperation between hydrological and atmospheric modelers and field scientists.

\section{Introduction and motivation}

As climate warms, a major hydrologic shift in precipitation phase from snow to rain is expected to occur across temperate regions that are reliant on mountain snowpacks for water resource provisioning (Bales et al., 2006; Barnett et al., 2005). Continued changes in precipitation phase are expected to alter snowpack dynamics and both streamflow timing and amounts (Cayan et al., 2001; Fritze et al., 2011; Luce and Holden, 2009; Klos et al., 2014; Berghuijs et al., 2014; Jepsen et al., 2016), increase rain-on-snow flooding (McCabe et al., 2007), and challenge our ability to make accurate water supply forecasts (Milly et al., 2008). Accurate estimations of precipitation inputs are required for effective hydrological 
modeling in both applied and research settings. Snow storage delays the transfer of precipitation to surface runoff, infiltration, and generation of streamflows (Fig. 1), affecting the timing and magnitude of peak flows (Wang et al., 2016), hydrograph recession (Yarnell et al., 2010), and the magnitude and duration of summer baseflow (Safeeq et al., 2014; Godsey et al., 2014). Moreover, the altered timing and rate of snow versus rain inputs can modify the partitioning of water to evapotranspiration versus runoff (Wang et al., 2013). Misrepresentation of precipitation phase within hydrologic models thus propagates into spring snowmelt dynamics (Harder and Pomeroy, 2013; Mizukami et al., 2013; White et al., 2002; Wen et al., 2013) and streamflow estimates used in water resource forecasting (Fig. 1). The persistence of streamflow error is particularly problematic for hydrological models that are calibrated on observed streamflows because this error can be compensated for by altering parameters that control other states and fluxes in the model (Minder, 2010; Shamir and Georgakakos, 2006; Kirchner, 2006). Expected changes in precipitation phase from climate warming presents a new set of challenges for effective hydrological modeling (Fig. 1). A simple yet essential issue for nearly all runoff generation questions is this: is precipitation falling as rain, snow, or a mix of both phases?

Despite advances in terrestrial process representation within hydrological models in the past several decades (Fatichi et al., 2016), most state-of-the-art models rely on simple empirical algorithms to predict precipitation phase. For example, nearly all operational models used by the National Weather Service River Forecast Centers in the United States use some type of temperature-based precipitation phase partitioning method (PPM) (Pagano et al., 2014). These are often single or double temperature threshold models that do not consider other conditions important to the hydrometeor's energy balance. Although forcing datasets for hydrological models are rapidly being developed for a suite of meteorological variables, to date no gridded precipitationphase product has been developed over regional to global scales. Widespread advances in both simulation of terrestrial hydrological processes and computational capabilities may have limited improvements on water resources forecasts without commensurate advances in PPMs.

Recent advances in PPMs incorporate effects of humidity (Harder and Pomeroy, 2013; Marks et al., 2013), atmospheric temperature profiles (Froidurot et al., 2014), and remote sensing of phase in the atmosphere (Minder, 2010; Lundquist et al., 2008). A challenge to improving and selecting PPMs is the lack of validation data. In particular, reliable ground-based observations of phase are sparse, collected at the point scale over limited areas, and are typically limited to research rather than operational applications (Marks et al., 2013). The lack of observations is particularly problematic in mountain regions where snow-rain transitions are widespread and critical for regional water resource evaluations (Klos et al., 2014). For example, direct visual observa-

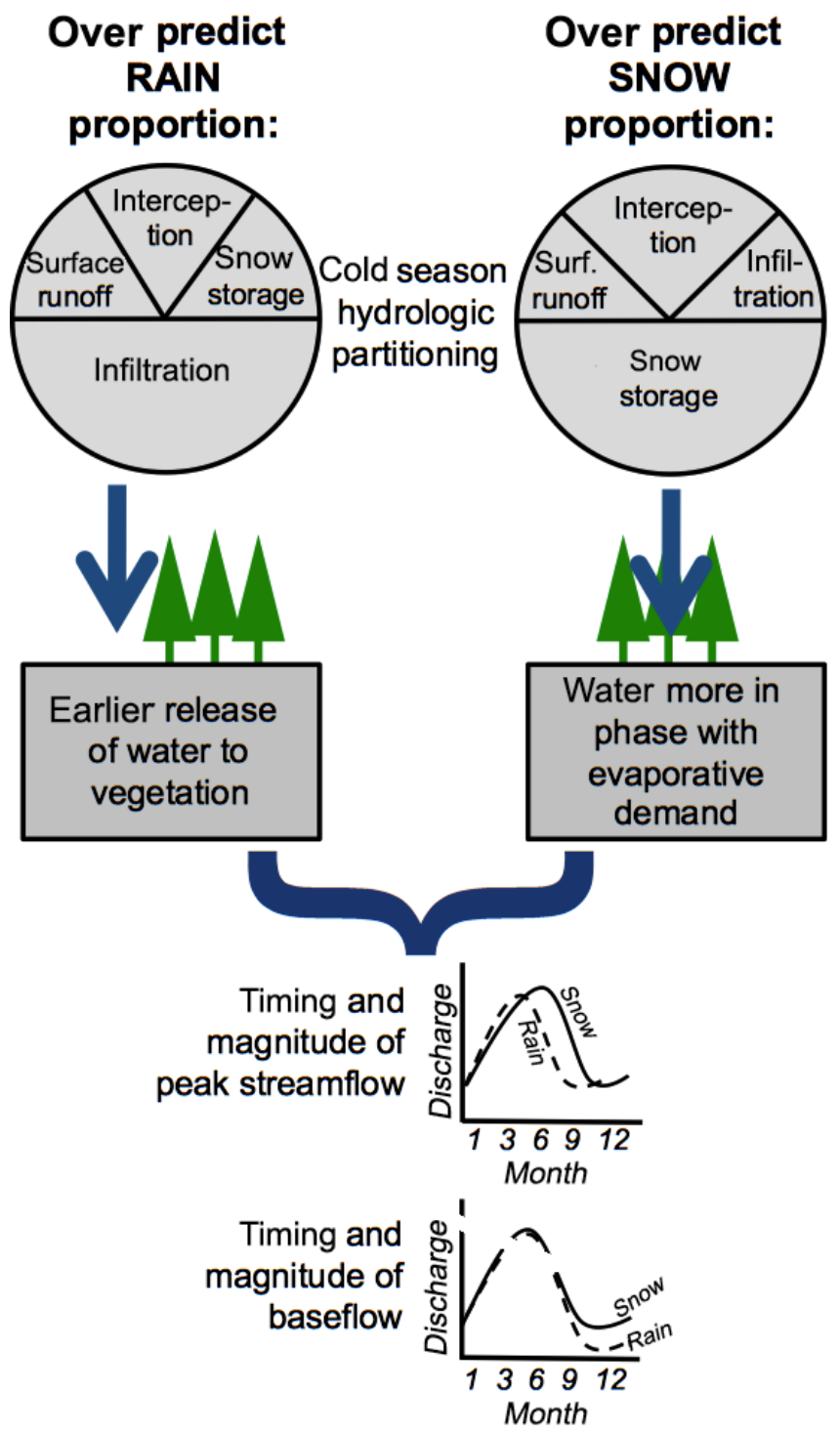

Figure 1. Precipitation phase has numerous implications for modeling the magnitude, storage, partitioning, and timing of water inputs and outputs. Potentially affecting important ecohydrological and streamflow quantities important for prediction.

tions have been widely used (Froidurot et al., 2014; Knowles et al., 2006; US Army Corps of Engineers, 1956), but are decreasing in number in favor of automated measurement systems. Automated systems use indirect methods to accurately estimate precipitation phase from hydrometeor characteristics (i.e., disdrometers), as well as coupled measurements that infer precipitation phase based on multiple lines of evidence (e.g., co-located snow depth and precipitation). Remote sensing is another indirect method that typically uses radar returns from ground and spaceborne platforms to infer hydrometeor temperature and phase. A comprehensive description of the advantages and disadvantages of current measurement strategies, as well as their correspondence with 


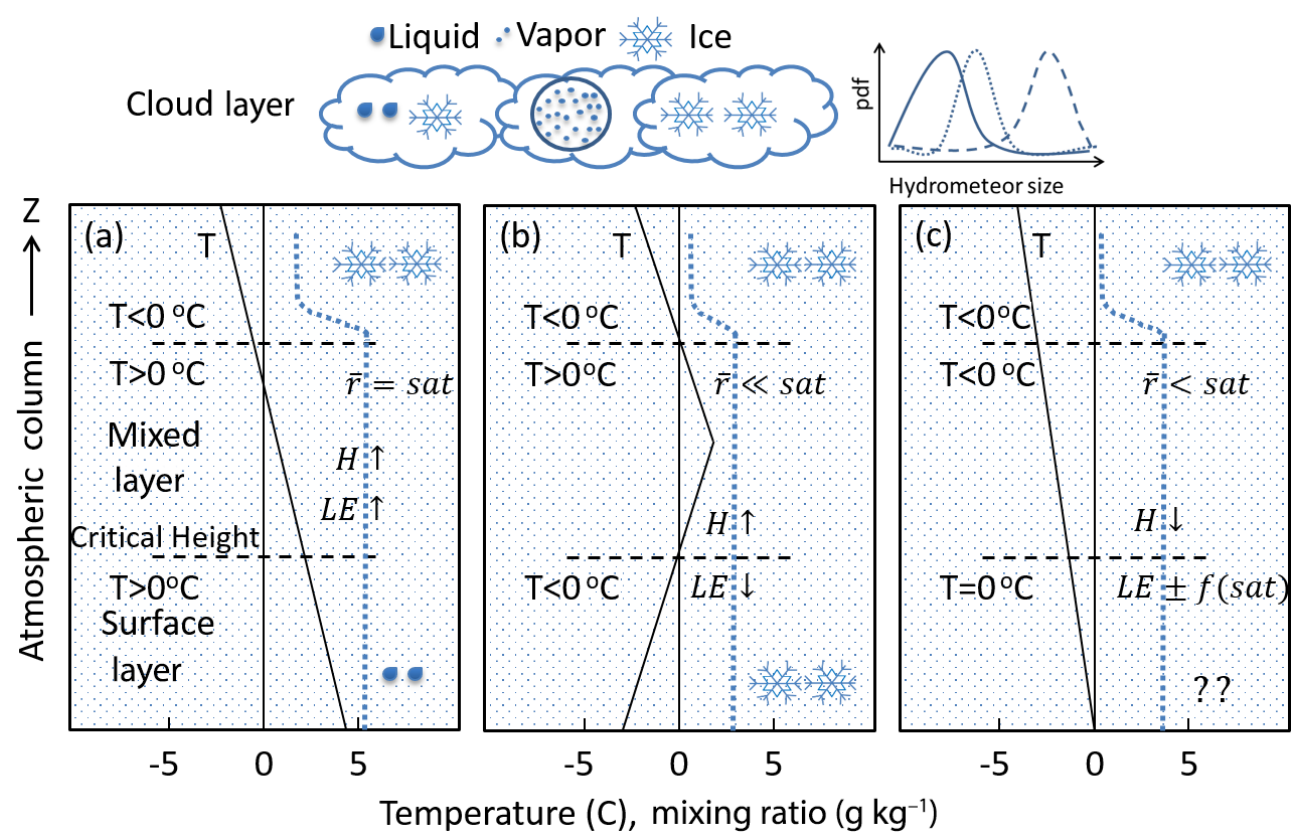

Figure 2. The phase of precipitation at the ground surface is strongly controlled by atmospheric profiles of temperature and humidity. While conditions exist that are relatively easy to predict rain (a) and snow (b), many conditions lead to complex heat exchanges that are difficult to predict with ground-based observations alone (c). The blue dotted line represents the mixing ratio. $H, L E, f$ (sat), and $r$ are abbreviations for sensible heat, latent heat of evaporation, function of saturation, and mixing ratio, respectively. The arrows after $H$ or $L E$ indicate the energy of the hydrometeor either increasing (up) or decreasing (down), which is controlled by other atmospheric conditions.

conventional PPMs, is needed to determine critical knowledge gaps and research opportunities.

New efforts are needed to advance PPMs to better inform hydrological models by integrating new observations, expanding the current observation networks, and testing techniques over regional variations in hydroclimatology. While calls to integrate atmospheric information are an important avenue for advancement (Feiccabrino et al., 2013), hydrological models ultimately require accurate and validated phase determination at the land surface. Moreover, any advancement that relies on integrating new information or developing a new PPM technique will require validation and training using ground-based observations. To make tangible hydrological modeling advancements, new techniques and datasets must be integrated with current modeling tools. The first step towards improved hydrological modeling in areas with mixed precipitation phase is educating the scientific community about current techniques and limitations that convey the areas where research is most needed.

Our review paper is motivated by a lack of a comprehensive description of the state-of-the-art PPMs and observation tools. Therefore, we describe the current state of the science in a way that clarifies the correspondence between techniques and observations, and highlights strengths and weaknesses in the current scientific understanding. Specifically, subsequent sections will review (1) the processes and physics that control precipitation phase as relevant to field hydrologists, (2) current available options for observing precipitation phase and related measurements common in remote field settings, (3) existing methods for predicting and modeling precipitation phase, and (4) research gaps that exist regarding precipitation-phase estimation. The overall objective is to convey a clear understanding of the diversity of tools available for PPMs in hydrological modeling and the advancements needed to improve predictions in complex terrain characterized by large spatiotemporal variations in precipitation phase.

\section{Processes and physics controlling precipitation phase}

Precipitation formed in the atmosphere is typically a solid in the mid-latitudes and its phase at the land surface is determined by whether it melts during falling (Stewart et al., 2015). Most hydrologic models do not simulate atmospheric processes and specify precipitation phase based on surface conditions alone (see Sect. 4.1), ignoring phase transformations in the atmosphere.

Several important properties that influence phase changes in the atmosphere are not included in hydrological models (Feiccabrino et al., 2012), such as temperature and precipitation characteristics (Theriault and Stewart, 2010), stability of the atmosphere (Theriault and Stewart, 2007), position of the $0{ }^{\circ} \mathrm{C}$ isotherm (Minder, 2010; Theriault and Stewart, 2010), interaction between hydrometeors (Stewart, 1992), and the 
atmospheric humidity profile (Harder and Pomeroy, 2013). The vertical temperature and humidity (represented by the mixing ratio) profile through which the hydrometeor falls typically consists of three layers, a top layer that is frozen $\left(T<0^{\circ} \mathrm{C}\right)$ in winter in temperate areas (Stewart, 1992), a mixed layer where $T$ can exceed $0^{\circ} \mathrm{C}$, and a surface layer that can be above or below $0^{\circ} \mathrm{C}$ (Fig. 2). The phase of precipitation at the surface partly depends on the phase reaching the top of the surface layer, which is defined as the critical height. The temperature profile and depth of the surface layer control the precipitation phase reaching the ground surface. For example, in Fig. 2a, if rain reaches the critical height, it may reach the surface as rain or ice pellets depending on small differences in temperature in the surface layer (Theriault and Stewart, 2010). Similarly, in Fig. 2b, if snow reaches the critical height, it may reach the surface as snow if the temperature in the surface layer is below freezing. However, in Fig. 2c, when the surface layer temperatures are close to freezing and the mixing ratios are neither close to saturation nor very dry, the phase at the surface is not easily determined by the surface conditions alone.

In addition to strong dependence on the vertical temperature and humidity profiles, precipitation phase is also a function of fall rate and hydrometeor size because they affect energy exchange with the atmosphere (Theriault et al., 2010). Precipitation rate influences the precipitation phase; for example, a precipitation rate of $10 \mathrm{~mm} \mathrm{~h}^{-1}$ reduces the amount of freezing rain by a factor of 3 over a precipitation rate of $1 \mathrm{~mm} \mathrm{~h}^{-1}$ (Theriault and Stewart, 2010) because there is less time for turbulent heat exchange with the hydrometeor. A solid hydrometeor that originates in the top layer and falls through the mixed layer can reach the surface layer as wet snow, sleet, or rain. This phase transition in the mixed layer is primarily a function of latent heat exchange driven by vapor pressure gradients and sensible heat exchange driven by temperature gradients. Temperature generally increases from the mixed layer to the surface layer causing sensible heat inputs to the hydrometeor. If these gains in sensible heat are combined with minimal latent heat losses resulting from low vapor pressure deficits, it is likely that the hydrometeor will reach the surface layer as rain (Fig. 2). However, vapor pressure in the mixed layer is often below saturation leading to latent energy losses and cooling of the hydrometeor coupled with diabatic cooling of the local atmosphere, which can produce snow or other forms of frozen precipitation at the surface even when temperatures are above $0^{\circ} \mathrm{C}$. Likewise, surface energetics affect local atmospheric conditions and dynamics, especially in complex terrain. For example, melting of the snowpack can cause diabatic cooling of the local atmosphere and affect the phase of precipitation, especially when air temperatures are very close to $0^{\circ} \mathrm{C}$ (Theriault et al., 2012). Many conditions lead to a combination of latent heat losses and sensible heat gains by hydrometeors (Fig. 2). Under these conditions it can be difficult to predict the phase of precipitation without sufficient information about humidity and temperature profiles, turbulence, hydrometeor size, and precipitation intensity.

Stability of the atmosphere can also influence precipitation phase. Stability is a function of the vertical temperature structure, which can be altered by vertical air movement and hence influence precipitation phase (Theriault and Stewart, 2007). Vertical air velocity changes the temperature structure by adiabatic warming or cooling due to pressure changes of descending and ascending air parcels, respectively. These changes in temperature can generate undersaturated or supersaturated conditions in the atmosphere that can also alter the precipitation phase. Even a very weak vertical air velocity $\left(<10 \mathrm{~cm} \mathrm{~s}^{-1}\right)$ significantly influences the phase and amount of precipitation formed in the atmosphere (Theriault and Stewart, 2007). The rain-snow line predicted by atmospheric models is very sensitive to these microphysics (Minder, 2010) and validating the microphysics across locations with complex physiography is challenging. Incorporation and validation of atmospheric microphysics is rarely achieved in hydrological applications (Feiccabrino et al., 2015).

\section{Current tools for observing precipitation phase}

\subsection{In situ observations}

In situ observations refer to methods wherein a person or instrument on-site records precipitation phase. We identify three classes of approaches that are used to observe precipitation phase including (1) direct observations, (2) coupled observations, and (3) proxy observations.

Direct observations simply involve a person on-site noting the phase of falling precipitation. Such data form the basis of many of the predictive methods that are widely used (Dai, 2008; Ding et al., 2014; US Army Corps of Engineers, 1956). Direct observations are useful for "manned" stations such as those operated by the US National Weather Service. Few research stations, however, have this benefit, particularly in many remote regions and in complex terrain. Direct observations are also limited in their temporal resolution and are typically reported only once per day, with some exceptions (Froidurot et al., 2014). Citizen scientist networks have historically provided valuable data to supplement primary instrumented observation networks. The National Weather Service Cooperative Observer Program (http://www.nws.noaa.gov/om/coop/what-is-coop.html; last access: 10 December 2016) is comprised of a network of volunteers recording daily observations of temperature and precipitation, including phase. The NOAA National Severe Storms Laboratory used citizen scientist observations of rain and snow occurrence to evaluate the performance of the Multi-Radar Multi-Sensor (MRMS) system in the meteorological Phenomena Identification Near the Ground (mPING) project (Chen et al., 2015). The mPING project has 
recently been expanded to allow citizen scientists worldwide to easily report precipitation phase and characteristics using GPS-enabled smartphone applications (http://mping.nssl. noaa.gov; last access: 12 April 2016). The Colorado Climate Center initiated the Community Collaborative Rain, Hail and Snow Network (CoCoRaHS), which supplies volunteers with low-cost instrumentation to observe precipitation characteristics, including phase, and enables observations to be reported on the project website (http://www.cocorahs.org/; last access: 10 December 2016). Although highly valuable, some limitations of this system include the imperfect ability of observers to identify mixed-phase events and the temporal extent of storms, as well as the lack of observations in both remote areas and during low-light conditions.

Coupled observations link synchronous measurements of precipitation with secondary observations to indicate phase. Secondary observations can include photographs of surrounding terrain, snow depth measurements, and/or measurements of ancillary meteorological variables. Photographs of vertical scales emplaced in the snow have been used to estimate snow accumulation depth, which can then be coupled with precipitation mass to determine density and phase (Berris and Harr, 1987; Floyd and Weiler, 2008; Garvelmann et al., 2013; Hedrick and Marshall, 2014; Parajka et al., 2012). Mixed-phase events, however, are difficult to quantify using coupled depth- and photographic-based techniques (Floyd and Weiler, 2008). Acoustic distance sensors, which are now commonly used to monitor the accumulation of snow (e.g., Boe, 2013), have similar drawbacks in mixed-phase events, but have been effectively applied to discriminate between snow and rain (Rajagopal and Harpold, 2016). Meteorological information such as temperature and relative humidity can be used to compute the phase of precipitation measured by bucket-type gauges. Unfortunately, this approach generally requires incorporating assumptions about the meteorological conditions that determine phase (see Sect. 4.1). Harder and Pomeroy (2013) used a comprehensive approach to determine the phase of precipitation. Every $15 \mathrm{~min}$ during their study period phase was determined by evaluating weighing bucket mass, tipping bucket depth, albedo, snow depth, and air temperature. Similarly, Marks et al. (2013) used a scheme based on co-located precipitation and snow depth to discriminate phase. A more involved expert decision-making approach by L'hôte et al. (2005) was based on six recorded meteorological parameters: precipitation intensity, albedo of the ground, air temperature, ground surface temperature, reflected long-wave radiation, and soil heat flux. The intent of most of these coupled observations was to develop datasets to evaluate PPMs. However, if observation systems such as these were sufficiently simple, they could have the potential to be applied operationally across larger meteorological monitoring networks encompassing complex terrain where snow comprises a large component of annual precipitation (Rajagopal and Harpold, 2016).
Proxy observations measure geophysical properties of precipitation to infer phase. The hot plate precipitation gauge introduced by Rasmussen et al. (2012), for example, uses a thin heated disk to accumulate precipitation and then measures the amount of energy required to melt snow or evaporate liquid water. This technique, however, requires a secondary measurement of air temperature to determine if the energy is used to melt snow or only evaporate rain. Disdrometers measure the size and velocity of hydrometeors. Although the most common application of disdrometer data is to determine the drop size distribution and other properties of rain, the phase of hydrometeors can be inferred by relating velocity and size to density. Some disdrometer technologies, which can be grouped into impact, imaging, and scattering approaches (Loffler-Mang et al., 1999), are better suited for describing snow than others. Impact disdrometers, first introduced by Joss and Waldvogel (1967), use an electromechanical sensor to convert the momentum of a hydrometeor into an electric pulse. The amplitude of the pulse is a function of drop diameter. Impact disdrometers have not been commonly used to measure solid precipitation due to the different functional relationships between drop size and momentum for solid and liquid precipitation. Imaging disdrometers use basic photographic principles to acquire images of the distribution of particles (Borrmann and Jaenicke, 1993; Knollenberg, 1970). The two-dimensional video disdrometer (2DVD) described by Kruger and Krajewski (2002) records the shadows cast by hydrometeors onto photodetectors as they pass through two sheets of light. The shape of the shadows enables computation of particle size, and shadows are tracked through both light sheets to determine velocity. Although initially designed to describe liquid precipitation, recent work has shown that the 2DVD can be used to classify snowfall according to microphysical properties of single hydrometeors (Bernauer et al., 2016). The 2DVD has been used to classify known rain and snow events, but little work has been performed to distinguish between liquid and solid precipitation. Scattering or optical disdrometers, measure the extinction of light passing between a source and a sensor (Hauser et al., 1984; Loffler-Mang et al., 1999). Like the other types, optical disdrometers were originally designed for rain, but have been periodically applied to snow (Battaglia et al., 2010; Lempio et al., 2007). In a comparison study by Caracciolo et al. (2006), the PARSIVEL optical disdrometer, originally described by Loffler-Mang et al. (1999), did not perform well against a 2DVD because of problems related to the detection of slow fall velocities for snow. It may be possible to use optical disdrometers to distinguish between rain, sleet, and snow based on the existence of distinct shapes of the size spectra for each precipitation type. More research on the relationship between air temperature and the size spectra produced by the optical disdrometer is needed (Lempio et al., 2007). In summary, disdrometers of various types are valuable tools for describing the properties of rain and snow, but require further testing and development 
to distinguish between rain and snow, as well as mixed-phase events.

\subsection{Ground-based remote sensing observations}

Ground-based remote sensing observations have been available for several decades to detect precipitation phase using radar. Until recently, most ground-based radar stations were operated as conventional Doppler systems that transmit and receive radio waves with single horizontal polarization. Developments in dual polarization ground radar, such as those that function as part of the US National Weather Service NEXRAD network (NOAA, 2016), have resulted in systems that transmit radio signals with both horizontal and vertical polarizations. In general, ground-based remote sensing observations, either single or dual polarization, remain underutilized for detecting precipitation phase and are challenging to apply in complex terrain (Table 3).

Ground-based remote sensing of precipitation phase using single-polarized radar systems depends on detecting the radar bright band. Radio waves transmitted by the radar system, are scattered by hydrometeors in the atmosphere, with a certain proportion reflected back towards the radar antenna. The magnitude of the measured reflectivity $(Z)$ is related to the size and the dielectric constant of falling hydrometeors (White et al., 2002). Ice particles aggregate as they descend through the atmosphere and their dielectric constant increases, in turn increasing $Z$ measured by the radar, creating the bright band, a layer of enhanced reflectivity just below the elevation of the melting level (Lundquist et al., 2008). Therefore, bright-band elevation can be used as a proxy for the "snow level", the bottom of the melting layer where falling snow transforms to rain (White et al., 2002, 2010).

Doppler vertical velocity (DVV) is another variable that can be estimated from single-polarized vertically profiling radar. DVV gives an estimate of the velocity of falling particles; as snowflakes melt and become liquid raindrops, the fall velocity of the hydrometeors increases. When combined with reflectivity profiles, DVV helps reduce false positive detection of the bright band, which may be caused by phenomena other than snow melting to rain (White et al., 2002). First, DVV and $Z$ are combined to detect the elevation of the bottom of the bright band. The algorithm then searches for maximum $Z$ above the bottom of the bright band and determines that to be the bright-band elevation (White et al., 2002). However, a test of this algorithm on data from a winter storm over the Sierra Nevada found root mean square errors of 326 to $457 \mathrm{~m}$ compared to ground observations when the bright-band elevation was assumed to represent the surface transition from snow to rain (Lundquist et al., 2008). Snow levels in mountainous areas, however, may also be overestimated by radar profiler estimates if they are unable to resolve spatial variations close to mountain fronts, since snow levels have been noted to persistently drop on windward slopes (Minder and Kingsmill, 2013). Despite the potential errors, the elevation of maximum $Z$ may be a useful proxy for snow levels in hydrometeorological applications in mountainous watersheds because maximum $Z$ will always occur below the freezing level (Lundquist et al., 2008; White et al., 2010)

Few published studies have explored the value of brightband-derived phase data for hydrologic modeling. Maurer and Mass (2006) compared the melting level from vertically pointing radar reflectivity against temperature-based methods to assess whether the radar approach could improve determination of precipitation phase at the ground level. In that study, the altitude of the top of the bright band was detected and applied across the study basin. Frozen precipitation was assumed to be falling in model pixels above the altitude of the melting level and liquid precipitation was assumed to be falling in pixels below the altitude of the melting layer (Maurer and Mass, 2006). Maurer and Mass (2006) found that incorporating radar-detected melting layer altitude improved streamflow simulation results. A similar study that used bright-band altitude to classify pixels according to surface precipitation type was not as conclusive; bright-band altitude data did not improve hydrologic model simulation results over those based on a temperature threshold (Mizukami et al., 2013). Also, the potential of the method is limited to the availability of vertically pointing radar; in complex, mountainous terrain the ability to estimate melting level becomes increasingly challenging with distance from the radar.

Dual-polarized radar systems generate more variables than traditional single-polarized systems. These polarimetric variables include differential reflectivity, reflectivity difference, the correlation coefficient, and specific differential phase. Polarimetric variables respond to hydrometeor properties such as shape, size, orientation, phase state, and fall behavior and can be used to assign hydrometeors to specific categories (Chandrasekar et al., 2013; Grazioli et al., 2015), or to improve bright-band detection (Giangrande et al., 2008).

Various hydrometeor classification algorithms have been applied to $X, C$, and $S$ band wavelengths. Improvements in these algorithms over recent years have seen hydrometeor classification become an operational meteorological product (see Grazioli et al., 2015 for an overview). For example, the US National Severe Storms Laboratory developed a fuzzylogic hydrometeor classification algorithm for warm-season convective weather (Park et al., 2009) and this algorithm has also been tested for cold-season events (Elmore, 2011). Its skill was tested against surface observations of precipitation type but the algorithm did not perform well in classifying winter precipitation because it could not account for refreezing of hydrometeors below the melting level (Fig. 2, Elmore, 2011). Unlike warm-season convective precipitation, the freezing level during a cold-season precipitation event can vary spatially. This phenomenon has prompted the use of polarimetric variables to first detect the melting layer, and then classify hydrometeors (Boodoo et al., 2010; Thompson et al., 2014). Although there has been some success in developing two-stage cold-season hydrometeor classification 
algorithms, there is little in the published literature that explores the potential contributions of these algorithms for partitioning snow and rain for hydrological modeling.

\subsection{Space-based remote sensing observations}

Spaceborne remote sensing observations typically use passive or active microwave sensors to determine precipitation phase (Table 3). Many of the previous passive microwave systems were challenged by coarse resolutions and difficulties retrieving snowfall over snow-covered areas. More recent active microwave systems are advantageous for detecting phase in terms of accuracy and spatial resolution, but remain largely unverified. Table 3 provides and overview of these space-based remote sensing technologies that are described in more detail below.

Passive microwave radiometers detect microwave radiation emitted by the Earth's surface or atmosphere. Passive microwave remote sensing has the potential for discriminating between rainfall and snowfall because microwave radiation emitted by the Earth's surface propagates through all but the densest precipitating clouds, meaning that radiation at microwave wavelengths directly interacts with hydrometeors within clouds (Olson et al., 1996; Ardanuy, 1989). However, the remote sensing of precipitation in microwave wavelengths and the development of operational algorithms is dominated by research focused on rainfall (Arkin and Ardanuy, 1989); by comparison, snowfall detection and observation has received less attention (Noh et al., 2009; Kim et al., 2008). This is partly explained by examining the physical processes within clouds that attenuate the microwave signal. Raindrops emit low levels of microwave radiation increasing the level of radiance measured by the sensor; in contrast, ice hydrometeors scatter microwave radiation, decreasing the radiance measured by a sensor (Kidd and Huffman, 2011). Land surfaces have a much higher emissivity than water surfaces, meaning that emission-based detection of precipitation is challenging over land because the high microwave emissions mask the emission signal from raindrops (Kidd, 1998; Kidd and Huffman, 2011). Thus, scattering-based techniques using medium to high frequencies are used to detect precipitation over land. Moreover, microwave observations at higher frequencies $(>89 \mathrm{GHz}$ ) have been shown to discriminate between liquid and frozen hydrometeors (Wilheit et al., 1982).

Retrieving snowfall over land areas from spaceborne microwave sensors can be even more challenging than for liquid precipitation because existing snow cover increases microwave emission. Depression of the microwave signal caused by scattering from airborne ice particles may be obscured by increased emission of microwave radiation from the snow-covered land surface. Kongoli et al. (2003) demonstrated an operational snowfall detection algorithm that accounts for the problem of existing snow cover. This group used data from the Advanced Microwave Sounding Unit-A (AMSU-A), a 15-channel atmospheric temperature sounder with a single high-frequency channel at $89 \mathrm{GHz}$ ), and AMSU-B, a 5-channel high-frequency microwave humidity sounder. Both sensors were mounted on the NOAA16 and 17 polar-orbiting satellites. While the algorithm worked well for warmer, opaque atmospheres, it was found to be too noisy for colder, clear atmospheres. Additionally, some snowfall events occur under warmer conditions than those that were the focus of the study (Kongoli et al., 2003). Kongoli et al. (2015) further adapted their methodology for the Advanced Technology Microwave Sounder (ATMS - onboard the polar-orbiting Suomi National Polar-orbiting Partnership satellite), a descendant of the AMSU sounders. The latest algorithm assesses the probability of snowfall using the logistic regression and the principal components of seven high-frequency bands at $89 \mathrm{GHz}$ and above. In testing, the Kongoli algorithm (Kongoli et al., 2015) has shown skill in detecting snowfall both at variable rates and when snowfall is lighter and occurs in colder conditions. An alternative algorithm by Noh et al. (2009) used physically based, radiative transfer modeling in an attempt to improve snowfall retrieval over land. In this case, radiative transfer modeling was used to construct an a priori database of observed snowfall profiles and corresponding brightness temperatures. The radiative transfer procedure yields likely brightness temperatures from modeling how ice particles scatter microwave radiation at different wavelengths. A Bayesian retrieval algorithm is then used to estimate snowfall over land by comparing measured and modeled brightness temperatures (Noh et al., 2009). The algorithm was tested during the early and late winter for large snowfall events (e.g., $60 \mathrm{~cm}$ depth in $12 \mathrm{~h}$ ). Late winter retrievals indicated that the algorithm overestimated snowfall over surfaces with significant snow accumulation.

While results have been promising, the spatial resolution at which ATMS and other passive microwave data are acquired is very coarse (15.8 to $74.8 \mathrm{~km}$ at nadir), making passive microwave approaches more applicable for regional to continental scales. Temporal resolution of the data acquisition is another challenge. AMSU instruments are mounted on eight satellites; the related ATMS is mounted on a single satellite and planned for two additional satellites. However, the satellites are polar orbiting, not geostationary, so it is probable that a precipitation event could occur outside the field of view of one of the instruments.

Spaceborne active microwave or radar sensors measure the backscattered signal from pulses of microwave energy emitted by the sensor itself. Much like the ground-based radar systems, the propagated microwave signal interacts with liquid and solid particles in the atmosphere and the degree to which the measured return signal is attenuated provides information on the atmospheric constituents. The advantage offered by spaceborne radar sensors over passive microwave is the capability to acquire more detailed sampling of the vertical profile of the atmosphere (Kulie and Bennartz, 2009). The first spaceborne radar capable of observing snowfall is 

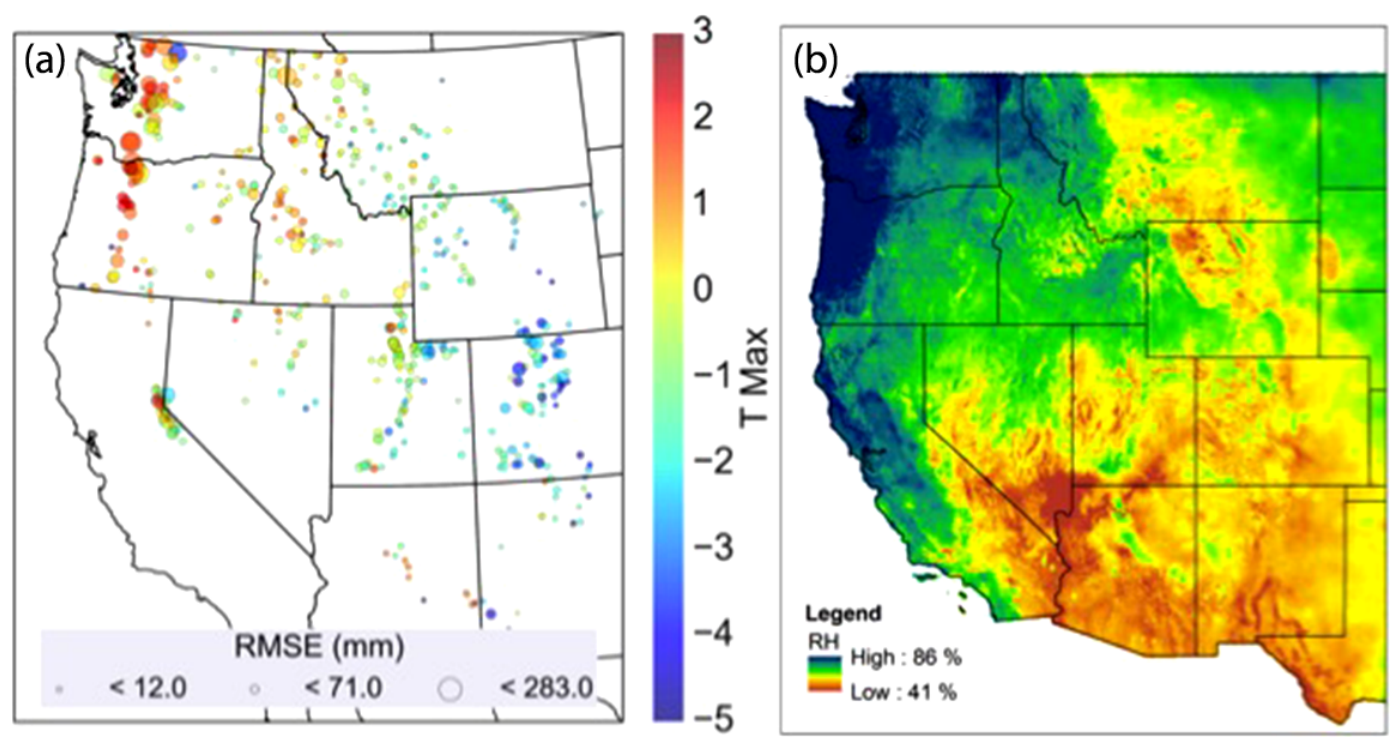

Figure 3. The optimized critical maximum daily temperature threshold that produced the lowest root mean square error (RMSE) in the prediction of snowfall at Snow Telemetry (SNOTEL) stations across the western USA (adapted from Rajagopal and Harpold, 2016). (b) Precipitation-day relative humidity averaged over 1981-2015 based on the Gridmet dataset (Abatzoglou, 2013).

the Cloud Profiling Radar (CPR) onboard CloudSat (2006 to present). The CPR operates at $94 \mathrm{GHz}$ with an alongtrack (or vertical) resolution of $\sim 1.5 \mathrm{~km}$. Retrieval of dry snowfall rate from CPR measurements of reflectivity have been shown to correspond with estimates of snowfall from ground-based radars at elevations of 2.6 and $3.6 \mathrm{~km}$ above mean sea level (Matrosov et al., 2008). Estimates at lower elevations, especially those in the lowest $1 \mathrm{~km}$, are contaminated by ground clutter. Alternative approaches, combining CPR data with ancillary data have been formulated to account for this challenge (Kulie and Bennartz, 2009; Liu, 2008). Known relationships between CPR reflectivity data and the scattering properties of non-spherical ice crystals are used to derive snowfall at a given elevation above mean sea level; below this elevation a temperature threshold derived from surface data is used to discriminate between rain and snow events. Liu (2008) used $2{ }^{\circ} \mathrm{C}$ as the snow-rain threshold, whereas Kulie and Bennartz (2009) used $0^{\circ} \mathrm{C}$ as the snow-rain threshold. Temperature thresholds have been the subject of much research and debate for discriminating precipitation phase, as is further discussed in Sect. 4.1.

CloudSat is part of the A-train or afternoon constellation of satellites, which includes Aqua, with the Moderate Resolution Imaging Spectrometer (MODIS) and the CloudAerosol Lidar and Infrared Pathfinder Satellite Observations (CALIPSO) spacecraft with cloud-profiling lidar. The sensors onboard A-train satellites provided the unique combination of data to create an operational snow retrieval product. The CPR level 2 snow profile product (2C-SNOWPROFILE) uses vertical profile data from the CPR, input from MODIS and the CPR, as well as weather forecast data to estimate near-surface snowfall (Kulie et al., 2016; Wood et al., 2013). The performance of 2C-SNOW-PROFILE was tested by Cao et al. (2014). This group found the product worked well in detecting light snow but performed less satisfactorily under conditions of moderate to heavy snow because of the non-stationary effects of attenuation on the returned radar signal.

The launch of the Global Precipitation Measurement (GPM) core observatory in February 2014 holds promise for the future deployment of operational snow detection products. Building on the success of the Tropical Rainfall Monitoring Mission (TRMM), the GPM core observatory sensors include the Dual-frequency Precipitation Radar (DPR) and GPM Microwave Imager (GMI). The GMI has $2 \mathrm{~mm}$ wave channels (166 and $183 \mathrm{GHz}$ ) that are specifically designed to detect and retrieve light rain and snow precipitation. These are more advanced than the sensors onboard the TRMM spacecraft and permit better quantification of the physical properties of precipitating particles, particularly over land at middle to high latitudes (Hou et al., 2014). Algorithms for the GPM mission are still under development, and are partly being driven by data collected during the GPM Cold-season Experiment (GCPEx) (Skofronick-Jackson et al., 2015). Using airborne sensors to simulate GPM and DPR measurements, one of the questions that the GCPEx hoped to address concerned the potential capability of data from the DPR and GMI to discriminate falling snow from rain or clear air (Skofronick-Jackson et al., 2015). The initial results reported by the GCPEx study echo some of the challenges recognized for ground-based single-polarized radar detection of snowfall. The relationship between radar reflectivity and snow- 
fall is not unique. For the GPM mission, it will be necessary to include more variables from dual-frequency radar measurements, multiple-frequency passive microwave measurements, or a combination of radar and passive microwave measurement (Skofronick-Jackson et al., 2015).

\section{Current tools for predicting precipitation phase}

\subsection{Prediction techniques from ground-based observations}

Discriminating between solid and liquid precipitation is often based on a near-surface air temperature threshold (Martinec and Rango, 1986; US Army Corps of Engineers, 1956; L'hôte et al., 2005). Four prediction methods have been developed that use near-surface air temperature for discriminating precipitation phase: (1) static threshold, (2) linear transition, (3) minimum and maximum temperature, and (4) sigmoidal curve (Table 1). A static temperature threshold applies a single temperature value, such as mean daily temperature, where all of the precipitation above the threshold is rain, and all below the threshold is snow. Typically this threshold temperature is near $0{ }^{\circ} \mathrm{C}$ (Lynch-Stieglitz, 1994; Motoyama, 1990), but was shown to be highly variable across both space and time (Kienzle, 2008; Motoyama, 1990; Braun, 1984; Ye et al., 2013). For example, Rajagopal and Harpold (2016) optimized a single temperature threshold at Snow Telemetry (SNOTEL) sites across the western USA to show regional variability from -4 to $3{ }^{\circ} \mathrm{C}$ (Fig. 3). A second discrimination technique is to linearly scale the proportion of snow and rain between a temperature for all rain $\left(T_{\text {rain }}\right)$ and a temperature for all snow $\left(T_{\text {snow }}\right)$ (Pipes and Quick, 1977; McCabe and Wolock, 2010; Tarboton et al., 1995). Linear threshold models have been parameterized slightly differently across studies, e.g., $T_{\text {snow }}=-1.0$ and $T_{\text {rain }}=3.0^{\circ} \mathrm{C}$ (McCabe and Wolock, 2010), $T_{\text {snow }}=-1.1$ and $T_{\text {rain }}=3.3^{\circ} \mathrm{C}$ (Tarboton et al., 1995), and $T_{\text {snow }}=0$ and $T_{\text {rain }}=5^{\circ} \mathrm{C}$ (McCabe and Wolock, 1999b). A third technique specifies a threshold temperature based on daily minimum and maximum temperatures to classify rain and snow, respectively, with a threshold temperature between the daily minimum and maximum producing a proportion of rain and snow (Leavesley et al., 1996). This technique can have a time-varying temperature threshold or include a $T_{\text {rain }}$ that is independent of daily maximum temperature. A fourth technique applies a sigmoidal relationship between mean daily (or sub-daily) temperature and the proportion or probability of snow versus rain. For example, one method derived for southern Alberta, Canada, employs a curvilinear relationship defined by two variables, a mean daily temperature threshold where $50 \%$ of precipitation is snow, and a temperature range where mixed-phase precipitation can occur (Kienzle, 2008). Another sigmoidal-based empirical model identified a hyperbolic tangent function defined by four parameters to estimate the conditional snow (or rain) frequency based on a global analysis of precipitationphase observations from over 15000 land-based stations (Dai, 2008). Selection of temperature-based techniques is typically based on available data, with a limited number of studies quantifying their relative accuracy for hydrological applications (Harder and Pomeroy, 2014).

Several studies have compared the accuracy of temperature-based PPM to one another and/or against an independent validation of precipitation phase. Sevruk (1984) found that only about $68 \%$ of the variability in monthly observed snow proportion in Switzerland could be explained by threshold temperature-based methods near $0^{\circ} \mathrm{C}$. An analysis of data from 15 stations in southern Alberta, Canada, with an average of $>30$ years of direct observations noted overestimations in the mean annual snowfall for static threshold $(8.1 \%)$, linear transition $(8.2 \%)$, minimum and maximum $(9.6 \%)$, and sigmoidal transition-based $(7.1 \%)$ methods (Kienzle, 2008). An evaluation of PPM at three sites in the Canadian Rockies by Harder and Pomeroy (2013) found the largest percent error to occur using a static threshold (11 to $18 \%$ ), followed by linear relationships ( -8 to $11 \%$ ), followed by sigmoidal relationships $(-3$ to $11 \%)$. Another study using 824 stations in China with $>30$ years of direct observations found accuracies of $51.4 \%$ using a static $2.2^{\circ} \mathrm{C}$ threshold and 35.7 to $47.4 \%$ using linear temperature-based thresholds (Ding et al., 2014). Lastly, for multiple sites across the rain-snow transition in southwestern Idaho, static temperature thresholds produced the lowest proportion $(68 \%)$ of snow, whereas a linear-based model produced the highest proportion $(75 \%)$ of snow (Marks et al., 2013). These accuracy assessments generally demonstrated that static threshold methods produced the greatest errors, whereas sigmoidal relationships produced the smallest errors, although variations to this general rule existed across sites. Near-surface humidity also influences precipitation phase (see Sect. 2). Three humidity-dependent precipitation-phase identification methods are found in the literature: (1) dew point temperature $\left(T_{\mathrm{d}}\right)$, (2) wet bulb temperature $\left(T_{\mathrm{w}}\right)$, and (3) psychometric energy balance. The dew point temperature is the temperature at which an air parcel with a fixed pressure and moisture content would be saturated. In one approach to account for measurement and instrument calibration uncertainties of $\pm 0.25^{\circ} \mathrm{C}$, both $T_{\mathrm{d}}$ and $T_{\mathrm{w}}$ below $-0.5^{\circ} \mathrm{C}$ were assumed to be all snow and above $+0.5^{\circ} \mathrm{C}$ all rain, with a linear relationship between the two being a proportional mix of snow and rain (Marks et al., 2013). $T_{\mathrm{d}}$ of $0.0^{\circ} \mathrm{C}$ performed consistently better than $T_{\mathrm{a}}$ in one study by Marks et al. (2001) while a $T_{\mathrm{d}}$ of $0.1^{\circ} \mathrm{C}$ for multiple stations in Sweden was less accurate than a $T_{\mathrm{a}}$ of $1.0^{\circ} \mathrm{C}$ (Feiccabrino et al., 2013). The wet or ice bulb temperature $\left(T_{\mathrm{w}}\right)$ is the temperature at which an air parcel would become saturated by evaporative cooling in the absence of other sources of sensible heat, and is the lowest temperature that falling precipitation can reach. Few studies have investigated the feasibility of $T_{\mathrm{w}}$ for precipitation-phase 
prediction (Olsen, 2003; Ding et al., 2014; Marks et al., 2013). $T_{\mathrm{w}}$ significantly improved prediction of precipitation phase over $T_{\mathrm{a}}$ at $15 \mathrm{~min}$ time steps, but only marginally improved predictions at daily time steps (Marks et al., 2013). Ding et al. (2014) developed a sigmoidal-phase probability curve based on $T_{\mathrm{w}}$ and an elevation that outperformed $T_{\mathrm{a}}$ threshold-based methods across a network of sites in China. Conceptually, the hydrometeor temperature $\left(T_{i}\right)$ is similar to $T_{\mathrm{w}}$ but is calculated using the latent heat and vapor density gradient. Use of computed $T_{i}$ values significantly improved precipitation-phase estimates over $T_{\mathrm{a}}$, particularly as timescales approached 1 day (Harder and Pomeroy, 2013).

There has been limited validation of humidity-based precipitation-phase prediction techniques against groundtruth observations. Ding et al. (2014) showed that a method based on $T_{\mathrm{w}}$ and elevation increased accuracy by $4.8-8.9 \%$ over several temperature-based methods. Their method was more accurate than the simpler $T_{\mathrm{w}}$-based method by Yamazaki (2001). Feiccabrino et al. (2013) showed that $T_{\mathrm{d}}$ misclassified $3.0 \%$ of snow and rain (excluding mixed-phase precipitation), whereas $T_{\mathrm{a}}$ only misclassified $2.4 \%$. Ye et al. (2013) found $T_{\mathrm{d}}$ less sensitive to phase discrimination under diverse environmental conditions and seasons than $T_{\mathrm{a}}$. Froidurot et al. (2014) evaluated several techniques with a critical success index (CSI) at sites across Switzerland to show the highest CSI values were associated with variables that included $T_{\mathrm{w}}$ or relative humidity $(\mathrm{CSI}=84-85 \%)$ compared to $T_{\mathrm{a}}(\mathrm{CSI}=78 \%)$. Marks et al. (2013) evaluated the time at which precipitation transitioned from snow to rain against field observations across a range of elevations and found that $T_{\mathrm{d}}$ most closely predicted the timing of phase change, whereas both $T_{\mathrm{a}}$ and $T_{\mathrm{w}}$ estimated earlier phase changes than observed. Harder and Pomeroy (2013) compared $T_{i}$ with field observations and found that error was $<10 \%$ when $T_{i}$ was allowed to vary with each daily time step and $>10 \%$ when $T_{i}$ was fixed at $0{ }^{\circ} \mathrm{C}$. The $T_{i}$ accuracy increased appreciably (i.e., 5-10\% improvement) when the temporal resolution was decreased from daily to hourly or $15 \mathrm{~min}$ time steps. The validation studies consistently showed improvements in accuracy by including humidity over PPMs based only on temperature.

Hydrological models employ a variety of techniques for phase prediction using ground-based observations (Table 2). All discrete hydrological models (i.e., not coupled to an atmospheric model) investigated used temperaturebased thresholds that did not consider the near-surface humidity. Moreover, most models use a single static temperature threshold that typically produces lower accuracy than multiple temperature methods. It should be noted that many of these hydrological models lump by elevation zone, which improves estimates of the snow to rain transition elevation and phase prediction accuracy in complex terrain compared to models without elevation zones. Hydrological models that are coupled to atmospheric models were more able to consider important controls on precipitation phase, such as hu- midity and atmospheric profiles. This compendium of model PPMs highlights the current shortcomings in phase prediction in conventional discrete hydrological models.

\subsection{Prediction techniques incorporating atmospheric information}

While many hydrologic models have their own formulations for determining precipitation phase at the ground, it is also possible to initialize hydrologic models with precipitationphase fraction, intensity, and volume from numerical weather simulation model output. Here we discuss the limitations of precipitation-phase simulation inherent to the Weather Research and Forecasting (WRF) model (Kaplan et al., 2012; Skamarock et al., 2008) and other atmospheric simulation models. The finest scale spatial resolution employed in atmospheric simulation models is $\sim 1 \mathrm{~km}$ and these models generate data at hourly or finer temporal resolutions. Regional climate models (RCMs) and global climate models (GCMs) are typically coarser than local mesoscale models. The physical processes driving both the removal of moisture from the air and the precipitation phase (Sect. 2) occur at much finer spatial and temporal resolutions in the real atmosphere than models typically resolve, i.e., $<1 \mathrm{~km}$. As with all numerical models, the representation of sub-grid-scale processes requires parameterization. At typical scales considered, characterization of mixed-phase processes within a condensing cloud depends on both cloud microphysics and kinematics of the surrounding atmosphere. Replicating cloud physics at the multi-kilometer scale requires empiricism. The $30+$ cloud microphysics parameterization options in the research version of WRF (Skamarock et al., 2008) vary in the number of classes described (cloud ice, cloud liquid, snow, rain, graupel, hail, etc.), and may or may not accurately resolve changes in hydrometeor phase and horizontal spatial location (due to wind) during precipitation. All microphysical schemes predict cloud water and cloud ice based on internal cloud processes that include a variety of empirical formulations or even simple lookup tables. These schemes vary greatly in their accuracy with "mixed-phase" schemes generally producing the most accurate simulations of precipitation phase in complex terrain, where much of the water is supercooled (Lin, 2007; Reisner et al., 1998; Thompson et al., 2004, 2008; Morrison et al., 2005; Zängl, 2007; Kaplan et al., 2012). Comprehensive validation of the microphysical schemes over different land surface types (warm maritime, flat prairie, etc.) with a focus on different snowfall patterns is lacking. In particular, in transition zones between mountains and plains or along coastlines, the complexity of the microphysics becomes even more extreme due the dynamics and interactions of differing air masses with distinct characteristics. The autoconversion and growth processes from cloud water or ice to hydrometeors contain a strong component of empiricism and, in particular, the nucleation media and their chemical composition. Different microphysical param- 


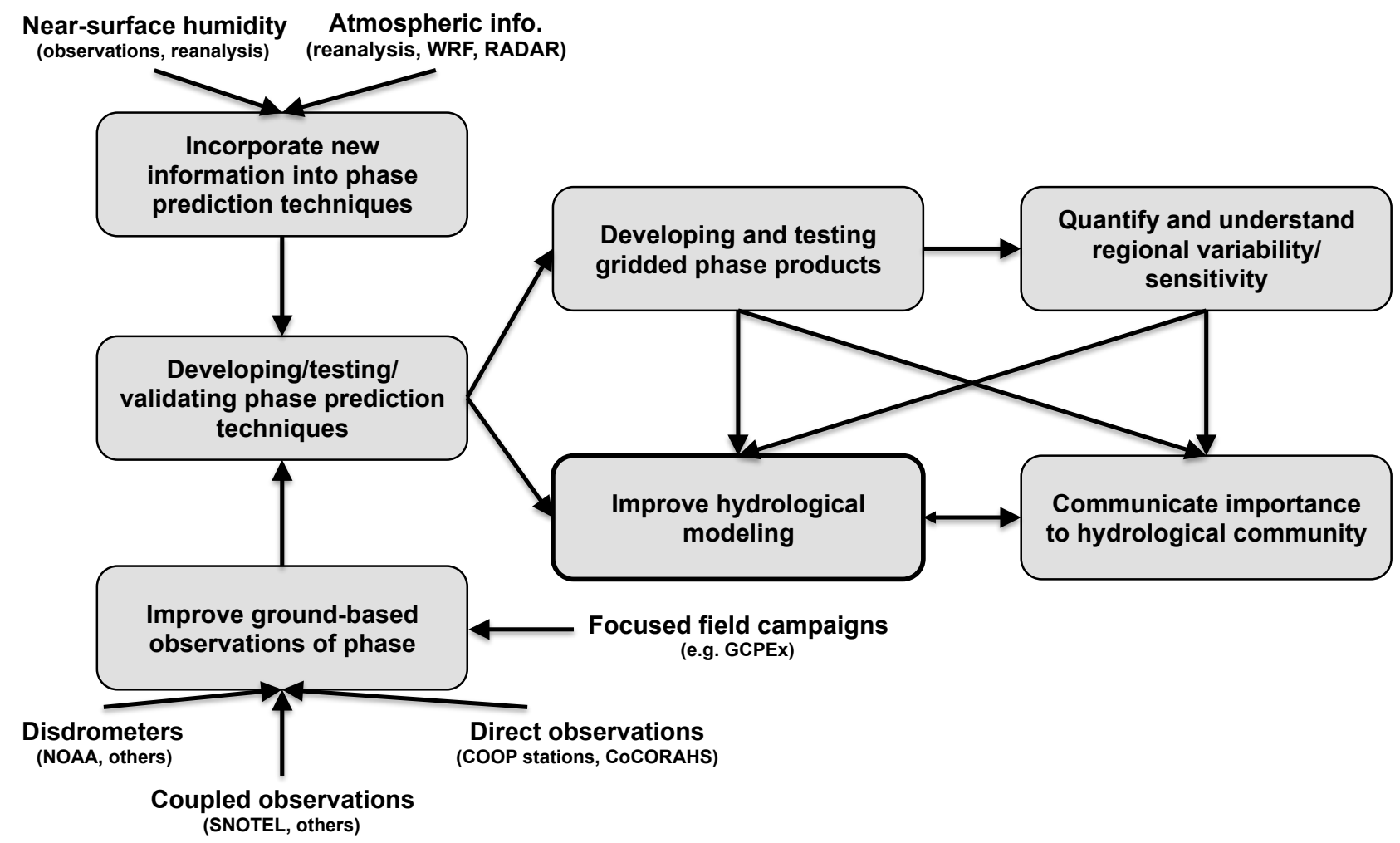

Figure 4. Conceptual representation of the research gaps and workflows needed to advance PPM and improve hydrological modeling.

eterizations lead to different spatial distributions of precipitation and produce varying vertical distributions of hydrometeors (Gilmore et al., 2004). Regardless, precipitation rates for each grid cell are averages requiring hydrological modelers to consider the effects of elevation, aspect, etc., in resolving precipitation-phase fractions for finer-scale models.

Numerical models that contain sophisticated cloud microphysics schemes allow for assimilation of additional remote sensing data beyond conventional synoptic/large-scale observations (balloon data). This is because the coarse spatial and temporal nature of radiosonde data results in the atmosphere being sensed imperfectly/incompletely compared with the scale of motion that weather simulation models can numerically resolve. These observational inadequacies are exacerbated in complex terrain, where precipitation-phase fraction can vary on small scales and radar can be blocked by topography and therefore rendered useless in the model initialization. Accurate generation of liquid and frozen precipitation from vapor requires accurate depiction of initial atmospheric moisture conditions (Kalnay and Cai, 2003; Lewis et al., 2006). In acknowledgement of the difficulty and uncertainty of initializing numerical simulation models, atmospheric modelers use the term "bogusing" to describe incorporation of individual observations at a point location into large-scale initial conditions in an effort to enhance the accuracy of the simulation (Eddington, 1989). They also em- ploy complex assimilation methodologies to force the early period of the model solutions during the time integration towards fine-scale observations (Kalnay and Cai, 2003; Lewis et al., 2006). These asynoptic or fine-scale data sources often substantially improve the accuracy of the simulations as time progresses.

Hydrologists are increasingly using output from atmospheric models to drive hydrologic models from daily to climatic or multi-decadal timescales (Tung and Haith, 1995; Pachauri, 2002; Wood et al., 2004; Rojas et al., 2011; Yucel et al., 2015). These atmospheric models suffer from the same data paucity and scale issues that likewise challenge the implementation and validation of hydrologic models. Uncertainties in their output, including precipitation volume and phase, begins with the initialization of the atmospheric model from measurements, increases with model choice and microphysics as well as turbulence parameterizations, and is a strong function of the scale of the model. The significance of these uncertainties varies by application, but should be acknowledged. Furthermore, these uncertainties are highly variable in character and magnitude from day to day and location to location. Thus, there has been very little published concerning how well atmospheric models predict precipitation phase. Finally, lack of ground measurements leaves hydrologists with no means to assess and validate atmospheric model predictions. 
Table 1. Mathematical expression for the four common temperature-based PPM to estimate snow fraction $(S)$ or snow frequency $(F)$ using the mean air temperature $\left(T_{\mathrm{a}}\right)$, maximum daily air temperature $\left(T_{\mathrm{a}-\mathrm{max}}\right)$, and/or minimum daily air temperature $\left(T_{\mathrm{a}-m i n}\right)$. The variable $T_{\mathrm{snow}}$ is air temperature when all precipitation $(P)$ is snow and $T_{\text {rain }}$ is the air temperature when all air precipitation is rain.

\begin{tabular}{|c|c|c|}
\hline Type & $\begin{array}{l}\text { Mathematical expression for snow fraction }(S) \\
\text { or snow frequency }(F)\end{array}$ & Reference(s) \\
\hline Static threshold & $S=\left\{\begin{array}{l}P \text { for } T_{\mathrm{a}} \leq T_{\text {snow }} \\
0 \text { for } T_{\mathrm{a}} \geq T_{\text {snow }}\end{array}\right.$ & Motoyama (1990) \\
\hline Linear transition & $S=\left\{\begin{array}{l}P \text { for } T_{\mathrm{a}} \leq T_{\text {snow }} \\
P\left(\frac{T_{\text {rain }}-T_{\mathrm{a}}}{T_{\text {rain }}-T_{\text {snow }}}\right) \text { for } T_{\text {snow }}<T_{\mathrm{a}}<T_{\text {rain }} \\
0 \text { for } T_{\mathrm{a}} \geq T_{\text {snow }}\end{array}\right.$ & McCabe and Wolock (1998b) \\
\hline Minimum and maximum temperature & 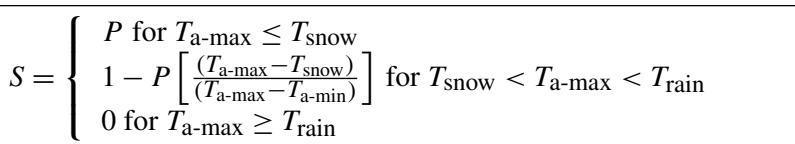 & Leavesley (1996) \\
\hline Sigmoidal curve & $S=P \times a\left[\tanh \left(b\left(T_{\mathrm{a}}-c\right)\right)-d\right] \quad F=a\left[\tanh \left(b\left(T_{\mathrm{a}}-c\right)\right)-d\right]$ & Dai (2008) \\
\hline
\end{tabular}

\section{Research gaps}

The incorrect prediction of precipitation phase leads to cascading effects on hydrological simulations (Fig. 1). Meeting the challenge of accurately predicting precipitation phase requires the closing of several critical research gaps (Fig. 4). Perhaps the most pressing challenge for improving PPMs is developing and employing new and improved sources of data. However, new data sources will not yield much benefit without effective incorporation into predictive models (Fig. 4). Additionally, both the scientific and management communities lack data products that can be readily understood and broadly used. Addressing these research gaps requires simultaneous engagement both within and between the hydrology and atmospheric observation and modeling communities. Changes to atmospheric temperature and humidity profiles from regional climate change will likely challenge conventional precipitation-phase prediction in ways that demand additional observations and improved forecasts.

We also highlight research gaps to improve relatively simple hydrological models without adding unnecessary complexity associated with sophisticated PPM approaches. For example, more efforts to verify the existing PPMs in different climatic environments and during specific hydrometeorological events could help determine various temperature thresholds (Table 1) to apply in of the existing models (Sect. 5.3). In addition, developing gridded precipitation-phase products may eliminate the need to make existing models more complex by applying more complex PPMs outside of those models, e.g., similar to precipitation distribution in existing gridded products used by many hydrological models. Ultimately, recognizing the sensitivity of hydrological model outcomes to PPMs and identifying which climates and applications require higher-phase prediction accuracy are crucial steps to determining the complexity of PPMs required for specific applications.

\subsection{Conduct focused field campaigns}

Intensive field campaigns are extremely effective approaches to address fundamental research gaps focused on the discrimination between rain, snow, and mixed-phase precipitation at the ground by providing opportunities to test novel sensors, collect detailed datasets to develop remote sensing retrieval algorithms, and improve PPM estimation methods. The recent GPM mission Cold-season Precipitation Experiment (GCPEx) is an example of such a campaign in noncomplex terrain, where simultaneous observations using arrays of both airborne and ground-based sensors were used to measure and characterize both solid and liquid precipitation (e.g., Skofronick-Jackson et al., 2015). Similar intensive field campaigns are needed in complex terrain that is frequently characterized by highly dynamic and spatially variable hydrometeorological conditions. Such campaigns are expensive to conduct, but can be implemented as part of operational nowcasting to develop rich data resources to advance scientific understanding as was very effectively done during the Vancouver Olympic Games in 2010 (Isaac et al., 2014; Joe et al., 2014). The research community should utilize existing datasets and capitalize on similar opportunities and expand environmental monitoring networks to simultaneously advance both atmospheric and hydrological understanding, especially in complex terrain spanning the rain-snow transition zone. 
Table 2. Common hydrological models and the phase partitioning method (PPM) technique employed. The citation referring to the original publication of the model is given.

\begin{tabular}{|c|c|c|}
\hline Model & PPM technique & Citations \\
\hline \multicolumn{3}{|c|}{ Discrete Models (not coupled) } \\
\hline $\mathrm{HBV}$ & Static threshold & Bergström (1995) \\
\hline Snowmelt Runoff Model & Static threshold & Martinec et al. (2008) \\
\hline SLURP & Static threshold & Kite (1995) \\
\hline UBC Watershed Model & Linear transition & Pipes and Quick (1977) \\
\hline PRMS model & Minimum and maximum temperature & Leavesley et al. (1996) \\
\hline USGS water budget & Linear transition between two mean temperatures & McCabe and Wolock (1999a) \\
\hline SAC-SMA (SNOW-17) & Static threshold & Anderson (2006) \\
\hline DHSVM & Linear transition (double check) & Wigmosta et al. (1994) \\
\hline SWAT & Threshold model & Arnold et al. (2012) \\
\hline RHESSys & Linear transition or input phase & Tague and Band (2004) \\
\hline HSPF & Air and dew point temperature thresholds & Bicknell et al. (1997) \\
\hline THE ARNO MODEL & Static threshold & Todini (1996) \\
\hline HEC-1 & Static threshold & HEC-1 (1998) \\
\hline MIKE SHE & Static threshold & MIKE-SHE user manual \\
\hline SWAP & Static threshold & Gusev and Nasonova (1998) \\
\hline BATS & Static threshold & Yang et al. (1997) \\
\hline Utah Energy Balance & Linear transition & Tarboton and Luce (1996) \\
\hline SNOBAL/ISNOBAL & Linear transition ${ }^{\mathrm{a}}$ & Marks et al. (2013) \\
\hline CRHM & Static threshold & Fang et al. (2013) \\
\hline GEOTOP & Linear transition & Zanotti et al. (2004) \\
\hline SNTHERM & Linear Transition & SNTHERM online documentation \\
\hline \multicolumn{3}{|l|}{ Offline LS models } \\
\hline Noah & Static threshold & Mitchell et al. (2005) \\
\hline VIC & Static threshold & VIC documentation \\
\hline CLASS & Multiple methods ${ }^{b}$ & Verseghy (2009) \\
\hline
\end{tabular}

${ }^{\mathrm{a}}$ By default. Temperature-phase-density relationship explicitly specified by user. ${ }^{\mathrm{b}} \mathrm{A}$ flag is specified, which switches between static threshold and linear transition.

\subsection{Incorporate humidity information}

Atmospheric humidity affects the energy budget of falling hydrometeors (Sect. 4.1), but is rarely considered in precipitation-phase prediction. The difficulty in incorporating humidity mainly arises from a lack of observations, both as point measurements and distributed gridded products. For example, while some reanalysis products have humidity information (i.e., National Centers for Environmental Prediction, NCEP reanalysis) they are at spatial scales (i.e., $>1^{\circ}$ ) that are too coarse for resolving precipitation phase in complex topography. Addition of high-quality aspirated humidity sensors at snow-monitoring stations, such as the SNOTEL network, would advance our understanding of humidity and its effects on precipitation phase in the mountains. Because dry air masses have regional variations controlled by storm tracks and proximity to water bodies, sensitivity of precipitation phase to humidity variations driven by regional warming remains relatively unexplored.

Although humidity datasets are relatively rare in mountain environments, some gridded data products exist that can be used to investigate the importance of humidity information.
Most interpolated gridded data products either do not include any measure of humidity (e.g., Daymet or WorldClim) or use daily temperature measurements to infer humidity conditions (e.g., PRISM). In complex terrain, air temperature can also vary dramatically at relatively small scales from ridge tops to valley bottoms due to cold air drainage (Whiteman et al., 1999) and hence can introduce errors into inferential techniques such as these. Potentially more useful are data assimilation products, such as NLDAS-2, that provide humidity and temperature values at $1 / 8$ th of a degree scale over the continental USA. In addition, several data reanalysis products are often available at 1-3-year lags from present, including NCEP/NCAR, NARR, and the 20th century reanalysis. Given the relatively sparse observations of humidity in mountain environments, the accuracy of gridded humidity products is rarely rigorously evaluated (Abatzoglou, 2013). More work is needed to understand the added skill provided by humidity datasets for predicting precipitation phase and its distribution over time and space.

We echo the call of Feiccabrino et al. (2015) for greater incorporation of atmospheric information into phase predic- 


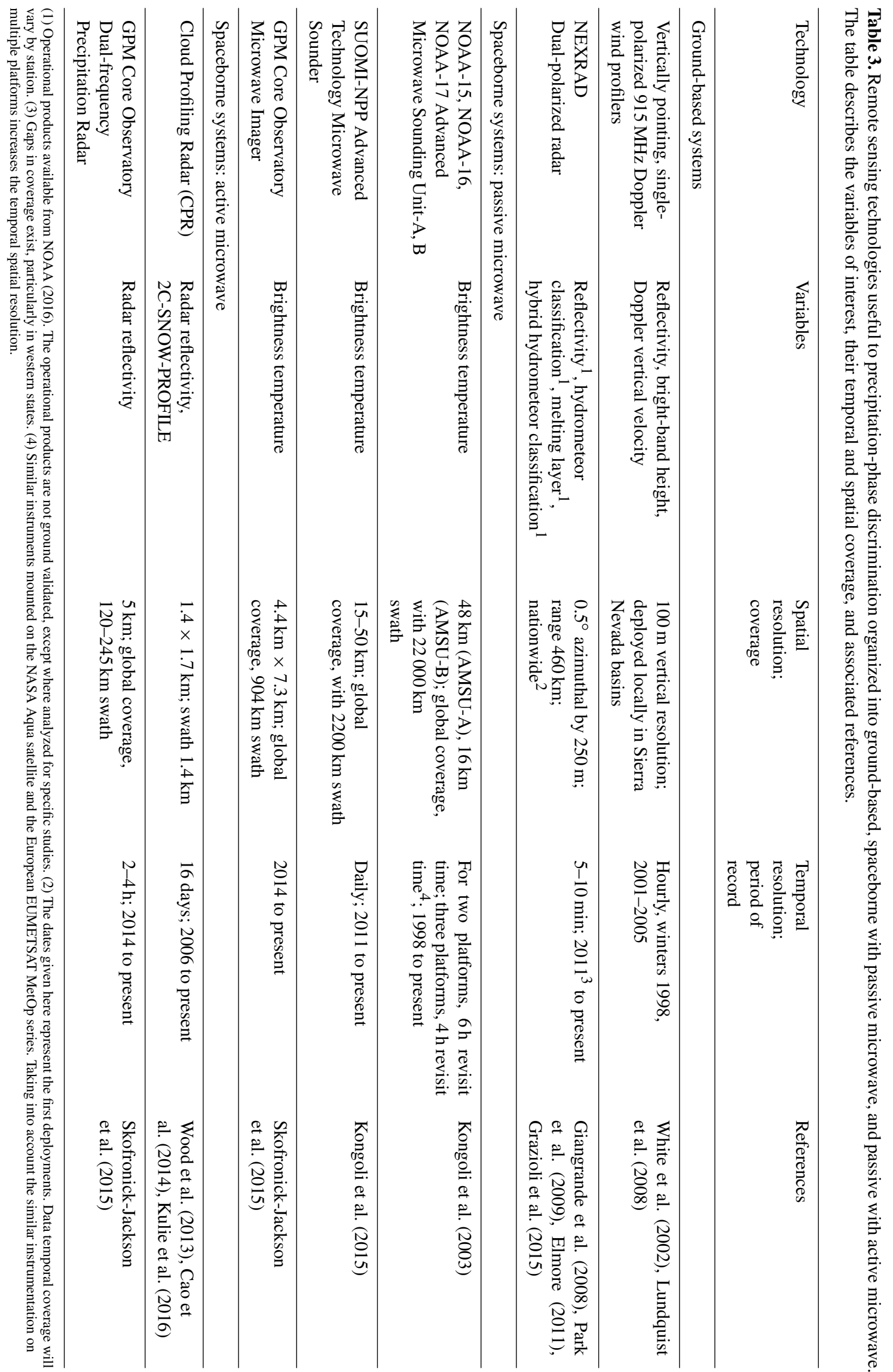


tion and additional verification of the skill in phase prediction provided by atmospheric information.

Several avenues exist to better incorporate atmospheric information into precipitation-phase prediction, including direct observations, remote sensing observations, and synthetic products. Radiosonde measurements made daily at many airports and weather forecasting centers have shown some promise for supplying atmospheric profiles of temperature and humidity (Froidurot et al., 2014). However, these data are only useful to initialize the larger-scale structure of temperature and water vapor, and may not capture local-scale variations in complex terrain. It is also their lack of temporal and spatial frequency that prevents their use in accurate precipitation-phase prediction, which is inherently a mesoscale problem, i.e., scales of motion $<100 \mathrm{~km}$. Atmospheric information on the bright-band height from Doppler radar has been utilized for predicting the altitude of the rain-snow transition (Lundquist et al., 2008; Minder, 2010), but has rarely been incorporated into hydrological modeling applications (Maurer and Mass, 2006; Mizukami et al., 2013). In addition to atmospheric observations, modeling products that assimilate observations or are fully physically based may provide additional information for precipitationphase prediction. Numerous reanalysis products (described in Sect. 2.2) provide temperature and humidity at different pressure levels within the atmosphere. To our knowledge, information from reanalysis products has yet to be incorporated into precipitation-phase prediction for hydrological applications. Bulk microphysical schemes used by meteorological models (e.g., WRF) provide physically based estimates of precipitation phase. These schemes capture a wide variety of processes, including evaporation, sublimation, condensation, and aggradation, and output between two and ten precipitation types. Historically, meteorological models have not been run at spatial scales capable of resolving convective dynamics (e.g., $<2 \mathrm{~km}$ ), which can exacerbate error in precipitation-phase prediction in complex terrain with a moist neutral atmosphere. Coarse meteorological models also struggle to produce pockets of frozen precipitation from advection of moisture plumes between mountain ranges and cold air wedged between topographic barriers. However, reduced computational restrictions on running these models at finer spatial scales and over large geographic extents (Rasmussen et al., 2012) are enabling further investigations into precipitation-phase change under historical and future climate scenarios. This suggests that finer dynamical downscaling is necessary to resolve precipitation phase, which is consistent with similar work attempting to resolve winter precipitation amounts in complex terrain (Gutmann et al., 2012). A potentially impactful area of research is to integrate this information into novel approaches to improve precipitationphase prediction skill.

\subsection{Disdrometer networks operating at high temporal resolutions}

An increase in the types and reliability of disdrometers over the last decade has provided a new suite of tools to more directly measure precipitation phase. Despite this new potential resource for distinguishing snow and rain, very limited deployments of disdrometers have occurred at the scale necessary to improve hydrologic modeling and rain-snow elevation estimates. The lack of disdrometer deployment likely arises from a number of potential limitations: (1) known issues with accuracy, (2) cost of these systems, and (3) power requirements needed for heating elements. These limitations are clearly a factor in procuring large networks and deploying disdrometers in complex terrain that is remote and frequently difficult to access. However, we advise that disdrometers offer numerous benefits that cannot be substituted with other measurements: (1) they operate at fine temporal scales, (2) they operate in low-light conditions that limit other direct observations, and (3) they provide land surface observations rather than precipitation phase in the atmosphere (as compared to more remote methods). Moreover, improvements in disdrometer and power supply technologies that address these limitations would remove restrictions on increased disdrometer deployment.

Transects of disdrometers spanning the rain-snow elevations of key mountain areas could add substantially to both prediction of precipitation phase for modeling purposes, as well as validating typical predictive models. We advocate for transects over key mountain passes where power is generally available and weather forecasts for travel are particularly important. In addition, co-locating disdrometers at longterm research stations, where precipitation-phase observations could be tied to micro-meteorological and hydrological observations, has distinct advantages. These areas often have power supplies and instrumentation expertise to operate and maintain disdrometer networks.

\subsection{Compare different indirect-phase measurement methods}

There is an important need to evaluate the accuracy of different PPMs to assess tradeoffs between model complexity and skill (Fig. 4). Given the potential for several types of observations to improve precipitation-phase prediction (Sect. 5.15.3), quantifying the relative skill provided by these different lines of evidence is a critical research gap. Although assessing relative differences between methods is potentially informative, comparison to ground-truth measurements is critical for assessing accuracy. Disdrometer measurements and video imaging (Newman et al., 2009) are ideal ground-truthing methods that can be employed at fine time steps and under a variety of conditions (Sect. 5.3). Less ideal for accuracy assessment studies are direct visual observations that are harder to collect at fine time steps and in low-light condi- 
tions. Similarly, employing coupled observations of precipitation and snow depth has been used to assess accuracy of different precipitation phase prediction methods (Marks et al., 2013; Harder and Pomeroy, 2013), but accuracy assessment of these techniques themselves are lacking under a wide range of contrasting hydrometeorological conditions.

A variety of accuracy assessments are needed that will require co-located distributed measurements. One critical accuracy assessment involves the consistency of different precipitation-phase prediction methods under different climate and atmospheric conditions. Assessing the effects of climate and atmospheric conditions requires measurements from a variety of sites covering a range of hydroclimatic conditions and record lengths that span the conceivable range of atmospheric conditions at a given site. Another important evaluation metric is the performance over different time steps. Harder and Pomeroy (2013) showed that hydrometeor and temperature-based prediction methods had errors that substantially decreased across shorter time steps. Identifying the effects of time step length on the accuracy of different prediction methods has been relatively unexplored, but is critical to select the most appropriate method for specific hydrological applications. Finally, the performance metrics used to assess accuracy should be carefully considered. The applications of precipitation phase prediction methods are diverse, necessitating a wide variety of performance metrics, including the probability of snow versus rain (Dai, 2008), the error in annual or total snow/rain accumulation (Rajagopal and Harpold, 2016), performance under extreme conditions of precipitation amount and intensity, determination of the snow-rain elevation (Marks et al., 2013), and uncertainty arising from measurement error and accuracy. Comparison of different metrics across a wide variety of sites and conditions is lacking but is greatly needed to advance hydrologic science in cold regions.

\subsection{Develop spatially resolved products}

Many hydrological applications will benefit from gridded data products that are easily integrated into standard hydrological models. Currently, very few options exist for gridded data precipitation-phase products. Instead, most hydrological models have some type of submodel or simple scheme that specifies precipitation phase as rain, snow, or mixed-phase precipitation (see Sect. 4). While testing PPMs with groundbased observations could lead to improved submodels, we believe development of gridded forcing data may be an easier and more effective solution for many hydrological modeling applications.

Gridded data products could be derived from a combination of remote sensing and existing synthetic products, but would need to be extensively evaluated. The NASA GPM mission is beginning to produce gridded precipitation-phase products at $3 \mathrm{~h}$ and $0.1^{\circ}$ resolution. However, GPM phase is measured at the top of the atmosphere, typically relies on simple temperature thresholds, and has yet to be validated with ground-based observations. Another existing product is the Snow Data Assimilation System (SNODAS) that estimates liquid and solid precipitation at the $1 \mathrm{~km}$ scale. However, the developers of SNODAS caution that it is not suitable for estimating storm totals or regional differences. Furthermore, to our knowledge the precipitation-phase product from SNODAS has not been validated with ground observations. We suggest the development of new gridded data products that utilize new PPMs (i.e., Harder and Pomeroy, 2013) and new and expanded observational datasets, such as atmospheric information and radar estimates. We advocate for the development of multiple gridded products that can be evaluated with surface observations to compare and contrast their strengths. Accurate gridded-phase products rely on the ability to represent the physics of water vapor and energy flows in complex terrain (e.g., Holden et al., 2010), where statistical downscaling methods are typically insufficient (Gutmann et al., 2012). This would also allow for ensembles of phase estimates to be used in hydrological models, similar to what is currently being done with gridded precipitation estimates.

\subsection{Characterization of regional variability and response to climate change}

The inclusion of new datasets, better validation of PPMs, and development of gridded data products will poise the hydrologic community to improve hydrological predictions and better quantify regional sensitivity of phase change to climate changes. Because broad-scale techniques applied to assess changes in precipitation phase and snowfall have relied on temperature, both regionally (Klos et al., 2014; Pierce and Cayan, 2013; Knowles et al., 2006) and globally (Kapnick and Delworth, 2013; O'Gorman, 2014), they have not fully considered the potential nonlinearities created by the absence of wet bulb depressions and humidity in assessment of sensitivity to changes in phase. Consequently, the effects of changes from snow to rain from warming and corresponding changes in humidity will be difficult to predict with current PPMs. Recent efforts by Rajagopal and Harpold (2016) have demonstrated that simple temperature thresholds are insufficient to characterize snow-rain transition across the western USA (Fig. 3), perhaps because of differences in humidity. An increased focus on future humidity trends, patterns, GCM simulation errors (Pierce et al., 2013), and availability of downscaled humidity products at increasingly finer scales (e.g., Abatzoglou, 2013; Pierce and Cayan, 2016) will enable detailed assessments of the relative role of temperature and humidity in future precipitation-phase changes. Recent remote sensing platforms, such as the GPM, may offer an additional tool to assess regional variability; however, the current GPM precipitation-phase product relies on wet bulb temperatures based on model output and not microwave-based observations (Huffman et al., 2015). In addition to issues with either spatial or temporal resolution or coverage, one 
of the main challenges in using remotely sensed data for distinguishing between frozen and liquid hydrometeors is the lack of validation. Where products have been validated, the results are usually only relevant for the locale of the study area. Spaceborne radar combined with ground-based radar offers perhaps the most promising solution, but given the non-unique relationship between radar reflectivity and snowfall, further testing is necessary in order to develop reliable algorithms.

Future work is needed to improve projections of changes in snowpack and water availability from regional to global scales. This local to sub-regional characterization is needed for water resource prediction and to better inform decision and policy makers. In particular, the ability to predict the transitional rain-snow elevations and its uncertainty is critical for a variety of end users, including state and municipal water agencies, flood forecasters, agricultural water boards, transportation agencies, and wildlife, forest, and land managers. Fundamental advancements in characterizing regional variability are possible by addressing the research challenges detailed in Sect. 5.1-5.5.

\section{Conclusions}

This review paper is a step towards communicating the potential bottlenecks in hydrological modeling caused by poor representation of precipitation phase (Fig. 1). Our goals are to demonstrate that major research gaps in our ability to develop PPMs are contributing to errors and reducing the predictive skill of hydrological models. By highlighting the research gaps that could advance the science of PPMs, we provide a road map for future advances (Fig. 4). While many of the research gaps are recognized by the community and are being pursued, including incorporating atmospheric and humidity information, others remain essentially unexplored (e.g., production of gridded data, widespread ground validation, and remote sensing validation).

The key points that must be communicated to the hydrologic community and its funding agencies can be distilled into the following two statements: (1) current PPMs are too simple to capture important processes and are not well validated for most locations, (2) the lack of sophisticated PPMs increases the uncertainty in estimation of hydrological sensitivity to changes in precipitation phase at local to regional scales. We advocate for better incorporation of new information (Sect. 5.1-5.2) and improved validation methods (Sect. 5.3-5.4) to advance our current PPMs and observations. These improved PPMs and remote sensing observations will be capable of developing gridded datasets (Sect. 5.5) and providing new insight that reduces the uncertainty of predicting regional changes from snow to rain (Sect. 5.6). Improved PPMs and existing phase products will also facilitate improvement of simpler hydrological models for which more complex PPMs are not justified. A concerted effort by the hydrological and atmospheric science communities to address the PPM challenge will remedy current limitations in hydrological modeling of precipitation phase, advance the understanding of cold regions hydrology, and provide better information to decision makers.

\section{Data availability}

Datasets used to create Fig. 3 are available for the SNOTEL site at the following link: https://wcc.sc.egov.usda.gov/ reportGenerator/ (last access: 19 December 2016) and for the University of Idaho Gridded Surface Meteorological Data at the following link: https://www.northwestknowledge.net/ metdata/data/ (last access: 19 December 2016).

Acknowledgements. This work was conducted as a part of an Innovation Working Group supported by the Idaho, Nevada, and New Mexico EPSCoR Programs and by the National Science Foundation under award numbers IIA-1329469, IIA-1329470, and IIA-1329513. Adrian Harpold was partially supported by USDA NIFA NEV05293. Adrian Harpold and Rina Schumer were supported by the NASA EPSCOR cooperative agreement no. NNX14AN24A. Timothy Link was partially supported by the Department of the Interior Northwest Climate Science Center (NW CSC) through a cooperative agreement no. G14AP00153 from the United States Geological Survey (USGS). Seshadri Rajagopal was partially supported by research supported by NSF/USDA grant (nos. 1360506 and 1360507) and startup funds provided by Desert Research Institute. The contents of this manuscript are solely the findings/opinions of the authors and do not necessarily represent the views of the NW CSC or the USGS. This manuscript is submitted for publication with the understanding that the United States Government is authorized to reproduce and distribute reprints for Governmental purposes.

Edited by: J. Seibert

Reviewed by: two anonymous referees

\section{References}

Abatzoglou, J. T.: Development of gridded surface meteorological data for ecological applications and modelling, Int. J. Climatol., 33, 121-131, doi:10.1002/joc.3413, 2013.

Anderson, E.: Snow Accumulation and Ablation Model - Snow17, available at: http://www.nws.noaa.gov/oh/hrl/nwsrfs/users_ manual/part2/_pdf/22snow17.pdf, (last access: 22 August 2016), 2006,

Arkin, P. A. and Ardanuy, P. E.: Estimating climatic-scale precipitation from space: a review, J. Climate, 2, 1229-1238, 1989.

Arnold, J. G., Kiniry, J. R., Srinivasan R., Williams, J. R, Haney, E. B., and Neitsch S. L.: SWAT Input/Output Documentation, Texas Water Resources Institute, TR-439, available at: http://swat. tamu.edu/media/69296/SWAT-IO-Documentation-2012.pdf, (last access: 22 August 2016), 2012,

Bales, R. C., Molotch, N. P., Painter, T. H., Dettinger, M. D., Rice, R., and Dozier, J.: Mountain hydrology of the 
western United States, Water Resour. Res., 42, W08432, doi:10.1029/2005wr004387, 2006.

Barnett, T. P., Adam, J. C., and Lettenmaier, D. P.: Potential impacts of a warming climate on water availability in snow-dominated regions, Nature, 438, 303-309, doi:10.1038/nature04141, 2005.

Battaglia, A., Rustemeier, E., Tokay, A., Blahak, U., and Simmer, C.: PARSIVEL Snow Observations: A Critical Assessment, J. Atmos. Ocean. Tech., 27, 333-344, doi:10.1175/2009jtecha1332.1, 2010.

Berghuijs, W. R., Woods, R. A., and Hrachowitz, M.: A precipitation shift from snow towards rain leads to a decrease in streamflow, Nature Climate Change, 4, 583-586, doi:10.1038/nclimate2246, 2014.

Bergström, S.: The HBV model, in: Computer Models of Watershed Hydrology, edited by: Singh, V. P., Water Resour. Publications, Highlands Ranch, CO, 443-476, 1995.

Bernauer, F., Hurkamp, K., Ruhm, W., and Tschiersch, J.: Snow event classification with a $2 \mathrm{D}$ video disdrometer - A decision tree approach, Atmos. Res., 172, 186-195, 2016.

Berris, S. N. and Harr, R. D.: Comparative snow accumulation and melt during rainfall in forested and clear-cut plots in the Western Cascades of Oregon, Water Resour. Res., 23, 135-142, doi:10.1029/WR023i001p00135, 1987.

Bicknell, B. R., Imhoff, J. C., Kittle Jr., J. L., Donigian Jr., A. S., and Johanson, R. C.: Hydrological Simulation Program-Fortran, User's manual for version 11: US Environmental Protection Agency, National Exposure Research Laboratory, Athens, Ga., EPA/600/R-97/080, p. 755, 1997.

Boe, E. T.: Assessing Local Snow Variability Using a Network of Ultrasonic Snow Depth Sensors, Master of Science in Hydrologic Sciences, Geosciences, Boise State, 2013.

Boodoo, S., Hudak, D., Donaldson, N., and Leduc, M.: Application of Dual-Polarization Radar Melting-Layer Detection Algorithm, J. Appl. Meteorol. Climatol., 49, 1779-1793, doi:10.1175/2010jamc2421.1, 2010.

Borrmann, S. and Jaenicke, R.: Application of microholography for ground-based in-situ measurements in stratus cloud layers - a case study, J. Atmos. Ocean. Tech., 10, 277-293, 1993.

Braun, L. N.: Simulation of snowmelt-runoff in lowland and lower alpine regions of Switzerland, Diss. Naturwiss, ETH Zürich, Nr. 7684 0000, edited by: Ohmura, A., Vischer, D., and Lang, H., 1984.

Cao, Q., Hong, Y., Chen, S., Gourley, J. J., Zhang, J., and Kirstetter, P. E.: Snowfall Detectability of NASA's CloudSat: The First Cross-Investigation of Its 2C-Snow-Profile Product and National Multi-Sensor Mosaic QPE (NMQ) Snowfall Data, Prog. Electromagn. Res., 148, 55-61, doi:10.2528/pier14030405, 2014.

Cayan, D. R., Kammerdiener, S. A., Dettinger, M. D., Caprio, J. M., and Peterson, D. H.: Changes in the onset of spring in the western United States, B. Am. Meteorol. Soc., 82, 399-415, 2001.

Chandrasekar, V., Keranen, R., Lim, S., and Moisseev, D.: Recent advances in classification of observations from dual polarization weather radars, Atmos. Res., 119, 97-111, doi:10.1016/j.atmosres.2011.08.014, 2013.

Chen, S., Gourley, J. J., Hong, Y., Cao, Q., Carr, N., Kirstetter, P.-E., Zhang, J., and Flamig, Z.: Using citizen science reports to evaluate estimates of surface precipitation type, B. Am. Meteorol. Soc., 187-193, doi:10.1175/BAMS-D-13-00247.1, 2015.
Dai, A.: Temperature and pressure dependence of the rain-snow phase transition over land and ocean, Geophys. Res. Lett., 35, L12802, doi:10.1029/2008g1033295, 2008.

Ding, B., Yang, K., Qin, J., Wang, L., Chen, Y., and He, X.: The dependence of precipitation types on surface elevation and meteorological conditions and its parameterization, J. Hydrol., 513, 154-163, doi:10.1016/j.jhydrol.2014.03.038, 2014.

Eddington, L. W.: Satellite-Derived Moisture-Bogusing Profiles for the North Atlantic Ocean, DTIC Document, 1989.

Elmore, K. L.: The NSSL Hydrometeor Classification Algorithm in Winter Surface Precipitation: Evaluation and Future Development, Weather Forecast., 26, 756-765, doi:10.1175/waf-d-1005011.1, 2011.

Fang, X., Pomeroy, J. W., Ellis, C. R., MacDonald, M. K., DeBeer, C. M., and Brown, T.: Multi-variable evaluation of hydrological model predictions for a headwater basin in the Canadian Rocky Mountains, Hydrol. Earth Syst. Sci., 17, 1635-1659, doi:10.5194/hess-17-1635-2013, 2013.

Fatichi, S., Vivoni, E. R., Ogden, F. L., Ivanov, V. Y., Mirus, B., Gochis, D., Downer, C. W., Camporese, M., Davison, J. H., Ebel, B., Jones, N., Kim, J., Mascaro, G., Niswonger, R., Restrepo, P., Rigon, R., Shen, C., Sulis, M., and Tarboton, D.: An overview of current applications, challenges, and future trends in distributed process-based models in hydrology, J. Hydrol., 537, 45-60, 2016.

Feiccabrino, J., Lundberg, A., and Gustafsson, D.: Improving surface-based precipitation phase determination through air mass boundary identification, Hydrol. Rese., 43, 179-191, doi:10.2166/nh.2012.060, 2013.

Feiccabrino, J., Gustafsson, D., and Lundberg, A.: Surface-based precipitation phase determination methods in hydrological models, Hydrol. Res., 44, 44-57, 2015.

Floyd, W. and Weiler, M.: Measuring snow accumulation and ablation dynamics during rain-on-snow events: innovative measurement techniques, Hydrol. Proc., 22, 4805-4812, doi:10.1002/hyp.7142, 2008.

Fritze, H., Stewart, I. T., and Pebesma, E.: Shifts in Western North American Snowmelt Runoff Regimes for the Recent Warm Decades, J. Hydrometeorol., 12, 989-1006, doi:10.1175/2011jhm1360.1, 2011.

Froidurot, S., Zin, I., Hingray, B., and Gautheron, A.: Sensitivity of Precipitation Phase over the Swiss Alps to Different Meteorological Variables, J. Hydrometeorol., 15, 685-696, doi:10.1175/jhm-d-13-073.1, 2014.

Garvelmann, J., Pohl, S., and Weiler, M.: From observation to the quantification of snow processes with a time-lapse camera network, Hydrol. Earth Syst. Sci., 17, 1415-1429, doi:10.5194/hess-17-1415-2013, 2013.

Giangrande, S. E., Krause, J. M., and Ryzhkov, A. V.: Automatic designation of the melting layer with a polarimetric prototype of the WSR-88D radar, J. Appl. Meteorol. Climatol., 47, 13541364, doi:10.1175/2007jamc1634.1, 2008.

Gilmore, M. S., Straka, J. M., and Rasmussen, E. N.: Precipitation Uncertainty Due to Variations in Precipitation Particle Parameters within a Simple Microphysics Scheme, Mon. Weather Rev., 132, 2610-2627, doi:10.1175/MWR2810.1, 2004.

Godsey, S. E., Kirchner, J. W., and Tague, C. L.: Effects of changes in winter snowpacks on summer low flows: case studies in the 
Sierra Nevada, California, USA, Hydrol. Proc., 28, 5048-5064, doi:10.1002/hyp.9943, 2014.

Grazioli, J., Tuia, D., and Berne, A.: Hydrometeor classification from polarimetric radar measurements: a clustering approach, Atmos. Meas. Tech., 8, 149-170, doi:10.5194/amt-8-149-2015, 2015

Gusev, E. M. and Nasonova, O. N.: Parameterization of Heat and Water Exchange on Land Surface for Coupling Hydrologic and Climate Models, Water Resour., 25, 421-431, 1998.

Gutmann, E. D., Rasmussen, R. M., Liu, C., Ikeda, K., Gochis, D., Clark, P. P., Dudhia, J., and Gregory, T.: A comparison of statistical and dynamical downscaling of winter precipitation over complex terrain, J. Clim., 25, 262-281, 2012.

Harder, P. and Pomeroy, J.: Estimating precipitation phase using a psychrometric energy balance method, Hydrol. Proc., 27, 19011914, doi:10.1002/hyp.9799, 2013.

Harder, P. and Pomeroy, J. W.: Hydrological model uncertainty due to precipitation-phase partitioning methods, Hydrol. Proc., 28, 4311-4327, 2014.

Hauser, D., Amayenc, P., and Nutten, B.: A new optical instrument for simultaneous measurement of raindrop diameter and fall speed distributions, Atmos. Oceanic Technol., 1, 256-259, 1984.

HEC-1: Flood Hydrograph Package, User's Manual, CPD1A, Version 4.1, available at: http://www.hec.usace.army. mil/publications/ComputerProgramDocumentation/HEC-1_ UsersManual_(CPD-1a).pdf, (last access: 22 August 2016), 1998,

Hedrick, A. R. and Marshall, H.-P.: Automated Snow Depth Measurements in Avalanche Terrain Using Time-Lapse Photography, 2014 International Snow Science Workshop, 2014.

Holden, Z. A., Abatzoglou, J. T., Luce, C. H., and Baggett, L. S.: Empirical downscaling of daily minimum air temperature at very fine resolutions in complex terrain, Agr. Forest Meteorol., 151, 1066-1073, doi:10.1016/j.agrformet.2011.03.011, 2011.

Hou, A. Y., Kakar, R. K., Neeck, S., Azarbarzin, A. A., Kummerow, C. D., Kojima, M., Oki, R., Nakamura, K., and Iguchi, T.: The global precipitation measurement mission, B. Am. Meteorol. Soc., 95, 701-722, 2014.

Isaac, G. A., Joe, P. I., Mailhot, J., Bailey, M., Bélair, S., Boudala, F. S., and Wilson, L. J.: Science of nowcasting Olympic weather for Vancouver 2010 (SNOW-V10): A World Weather Research Programme project, Pure Appl. Geophys., 171, 1-24, doi:10.1007/s00024-012-0579-0, 2014.

Jepsen, S. M., Harmon, T. C., Meadows, M. W., and Hunsaker, C. T.: Hydrogeologic influence on changes in snowmelt runoff with climate warming: Numerical experiments on a mid-elevation catchment in the Sierra Nevada, USA, J. Hydrol., 533, 332-342, doi:10.1016/j.jhydrol.2015.12.010, 2016.

Joe, P., Scott, B., Doyle, C., Isaac, G., Gultepe, I., Forsyth, D., and Boudala, F. The monitoring network of the Vancouver 2010 Olympics, Pure Appl. Geophys., 171, 25-58, doi:10.1007/s00024-012-0588-z, 2014.

Joss, J. and Waldvogel, A.: Ein Spektograph fuer Niederschlagstropfen mit automatischer Auswertung, Pure Appl. Geophys., 68, 240-246, 1967.

Kalnay, E. and Cai, M.: Impact of urbanization and land-use change on climate, Nature, 423, 528-531, doi:10.1038/nature01675, 2003.
Kaplan, M. L., Vellore, R. K., Marzette, P. J., and Lewis, J. M.: The role of windward-side diabatic heating in Sierra Nevada spillover precipitation, J. Hydrometeorol., 13, 1172-1194, 2012.

Kapnick, S. B. and Delworth, T. L.: Controls of global snow under a changed climate, J. Clim., 26, 5537-5562, 2013.

Kidd, C.: On rainfall retrieval using polarization-corrected temperatures, Int. J. Remote Sens., 19, 981-996, doi:10.1080/014311698215829, 1998.

Kidd, C. and Huffman, G.: Global precipitation measurement, Meteorol. Appl., 18, 334-353, doi:10.1002/met.284, 2011.

Kienzle, S. W.: A new temperature based method to separate rain and snow, Hydrol. Proc., 22, 5067-5085, doi:10.1002/hyp.7131, 2008.

Kim, M. J., Weinman, J. A., Olson, W. S., Chang, D. E., SkofronickJackson, G., and Wang, J. R.: A physical model to estimate snowfall over land using AMSU-B observations, J. Geophys. Res.Atmos., 113, D09201, doi:10.1029/2007jd008589, 2008.

Kirchner, J. W.: Getting the right answers for the right reasons: Linking measurements, analyses, and models to advance the science of hydrology, Water Resour. Res., 42, W03S04, doi:10.1029/2005wr004362, 2006.

Kite, G.: The HBV model, in: Computer Models of Watershed Hydrology, edited by: Singh, V.P., Water Resources Publications, Highlands Ranch, CO, 443-476, 1995.

Klos, P. Z., Link, T. E., and Abatzoglou, J. T.: Extent of the rain-snow transition zone in the western US under historic and projected climate, Geophys. Res. Lett., 41, 4560-4568, doi:10.1002/2014g1060500, 2014.

Knollenberg, R. G.: Some results of measurements of latent heat released from seeded stratus, B. Am. Meteorol. Soc., 51, 580592, 1970.

Knowles, N., Dettinger, M. D., and Cayan, D. R.: Trends in snowfall versus rainfall in the Western United States, J. Clim., 19, 45454559, 2006.

Kongoli, C., Pellegrino, P., Ferraro, R. R., Grody, N. C., and Meng, H.: A new snowfall detection algorithm over land using measurements from the Advanced Microwave Sounding Unit (AMSU), Geophys. Res. Lett., 30, 1756-1763, doi:10.1029/2003g1017177, 2003.

Kongoli, C., Meng, H., Dong, J., and Ferraro, R.: A snowfall detection algorithm over land utilizing high-frequency passive microwave measurements-Application to ATMS, J. Geophys. Res.Atmos., 120, 1918-1932, doi:10.1002/2014jd022427, 2015.

Kruger, A. and Krajewski, W. F.: Two-dimensional video disdrometer: A description, J. Atmos. Ocean. Tech., 19, 602-617, doi:10.1175/1520-0426(2002)019<0602:tdvdad>2.0.co;2, 2002.

Kulie, M. S., Milani, L., Wood, N. B., Tushaus, S. A., Bennartz, R., and L'Ecuyer, T. S.: A Shallow Cumuliform Snowfall Census Using Spaceborne Radar, J. Hydrometeorol., 17, 1261-1279, doi:10.1175/jhm-d-15-0123.1, 2016.

Leavesley, G. H., Restrepo, P. J., Markstrom, S. L., Dixon, M., and Stannard, L. G.: The Modular Modeling System (MMS): User's Manual, US Geological Survey, Denver, COOpen File Report 96151, 1996.

Lempio, G. E., Bumke, K., and Macke, A.: Measurement of solid precipitation with an optical disdrometer, Adv. Geosci., 10, 9197, 2007. 
Lewis, J., Lakshmivarahan, S., and Dhall, S.: Dynamic Data Assimilation: A Least Squares Approach, Cambridge Univ. Press, 745 pp., 2006.

L'hôte, Y., Chevallier, P., Coudrain, A., Lejeune, Y., and Etchevers, P.: Relationship between precipitation phase and air temperature: comparison between the Bolivian Andes and the Swiss Alps/Relation entre phase de précipitation et température de l'air: comparaison entre les Andes Boliviennes et les Alpes Suisses, Hydrol. Sci. J., 50, 989-997, 2005.

Lin, Y.-L.: Mesoscale Dynamics, Cambridge University Press, 630 pp., 2007.

Liu, G.: Deriving snow cloud characteristics from CloudSat observations, J. Geophys. Res.-Atmos., 113, D00A09, doi:10.1029/2007jd009766, 2008.

Loffler-Mang, M., Kunz, M., and Schmid, W.: On the performance of a low-cost K-band Doppler radar for quantitative rain measurements, J. Atmos. Ocean. Tech., 16, 379-387, doi:10.1175/1520-0426(1999)016<0379:otpoal>2.0.co;2, 1999.

Luce, C. H. and Holden, Z. A.: Declining annual streamflow distributions in the Pacific Northwest United States, 1948-2006, Geophys. Res. Lett., 36, L16401, doi:10.1029/2009g1039407, 2009.

Lundquist, J. D., Neiman, P. J., Martner, B., White, A. B., Gottas, D. J., and Ralph, F. M.: Rain versus snow in the Sierra Nevada, California: Comparing Doppler profiling radar and surface observations of melting level, J. Hydrometeorol., 9, 194211, doi:10.1175/2007jhm853.1, 2008.

Lynch-Stieglitz, M.: The development and validation of a simple snow model for the GISS GCM, J. Clim., 7, 1842-1855, 1994.

Marks, D., Link, T., Winstral, A., and Garen, D.: Simulating snowmelt processes during rain-on-snow over a semi-arid mountain basin, Ann. Glaciol., 32, 195-202, 2001.

Marks, D., Winstral, A., Reba, M., Pomeroy, J., and Kumar, M.: An evaluation of methods for determining during-storm precipitation phase and the rain/snow transition elevation at the surface in a mountain basin, Adv. Water Resour., 55, 98-110, 2013.

Martinec, J. and Rango, A.: Parameter values for snowmelt runoff modelling, J. Hydrol., 84, 197-219, 1986.

Martinec, J., Rango, A., and Roberts, R.: Snowmelt Runoff Model, User's Manual, available at: http://aces.nmsu.edu/pubs/research/ weather_climate/SRMSpecRep100.pdf, (last access: 22 August 2016), 2008,

Matrosov, S. Y., Shupe, M. D., and Djalalova, I. V.: Snowfall retrievals using millimeter-wavelength cloud radars, J. Appl. Meteorol. Climatol., 47, 769-777, doi:10.1175/2007jamc1768.1, 2008.

Maurer, E. P. and Mass, C.: Using radar data to partition precipitation into rain and snow in a hydrologic model, J. Hydrol. Engin., 11, 214-221, doi:10.1061/(asce)10840699(2006)11:3(214), 2006.

McCabe, G. J. and Wolock, D. M.:General-circulation-model simulations of future snowpack in the western United States1, JAWRA J. Am. Water Resour. Assoc., 35, 1473-1484, 1999a.

McCabe, G. J. and Wolock, D. M.: Recent Declines in Western US Snowpack in the Context of Twentieth-Century Climate Variability, Earth Interact., 13, 1-15, doi:10.1175/2009EI283.1, 1999 b.

McCabe, G. J. and Wolock, D. M.: Long-term variability in Northern Hemisphere snow cover and associations with warmer winters, Climatic Change, 99, 141-153, 2010.
McCabe, G. J., Clark, M. P., and Hay, L. E.: Rain-on-snow events in the western United States, Bull. Am. Meteorol. Soc., 88, 319328, doi:10.1175/bams-88-3-319, 2007.

MIKE-SHE User Manual, available at: ftp://ftp.cgs.si/Uporabniki/ UrosZ/mike/Manuals/MIKE_SHE/MIKE_SHE.htm, last acces: 22 August 2016

Milly, P. C. D., Betancourt, J., Falkenmark, M., Hirsch, R. M., Kundzewicz, Z. W., Lettenmaier, D. P., and Stouffer, R. J.: Climate change - Stationarity is dead: Whither water management?, Science, 319, 573-574, doi:10.1126/science.1151915, 2008.

Minder, J. R.: The Sensitivity of Mountain Snowpack Accumulation to Climate Warming, J. Clim., 23, 2634-2650, doi:10.1175/2009jcli3263.1, 2010.

Minder, J. R. and Kingsmill, D. E.: Mesoscale Variations of the Atmospheric Snow Line over the Northern Sierra Nevada: Multiyear Statistics, Case Study, and Mechanisms, J. Atmos. Sci., 70, 916-938, doi:10.1175/jas-d-12-0194.1, 2013.

Mitchell K., Ek, M., Wong, V., Lohmann, D., Koren, V., Schaake, J., Duan, Q., Gayno, G., Moore, B., Grunmann, P., Tarpley, D., Ramsay, B., Chen, F., Kim, J., Pan, H.L., Lin, Y., Marshall, C., Mahrt, L., Meyers, T., and Ruscher, P.: Noah LandSurface Model, User's Guide, version 2.7.1, available at: ftp: //ftp.emc.ncep.noaa.gov/mmb/gcp/ldas/noahlsm/ver_2.7.1, (last access: 22 August 2016), 2005.

Mizukami, N., Koren, V., Smith, M., Kingsmill, D., Zhang, Z. Y., Cosgrove, B., and Cui, Z. T.: The Impact of Precipitation Type Discrimination on Hydrologic Simulation: Rain-Snow Partitioning Derived from HMT-West Radar-Detected Brightband Height versus Surface Temperature Data, J. Hydrometeorol., 14, 11391158, doi:10.1175/jhm-d-12-035.1, 2013.

Morrison, H., Curry, J., and Khvorostyanov, V.: A new doublemoment microphysics parameterization for application in cloud and climate models, Part I: Description, J. Atmos. Sci., 62, 1665$1677,2005$.

Motoyama, H.: Simulation of seasonal snowcover based on air temperature and precipitation, J. Appl. Meteorol., 29, 1104-1110, 1990.

Newman, A. J., Kucera, P. A., and Bliven, L. F.: Presenting the snowflake video imager (SVI), J. Atmos. Ocean. Tech., 26, 167179, doi:10.1175/2008jtecha1148.1, 2009.

NOAA: NEXRAD Data Archive, Inventory and Access, available at: https://www.ncdc.noaa.gov/nexradinv/, last access: 11 October 2016.

Noh, Y. J., Liu, G. S., Jones, A. S., and Haar, T. H. V.: Toward snowfall retrieval over land by combining satellite and in situ measurements, J. Geophys. Res.-Atmos., 114, D24205, doi:10.1029/2009jd012307, 2009.

O'Gorman, P. A.: Contrasting responses of mean and extreme snowfall to climate change, Nature, 512, 416-418, 2014.

Olsen, A.: Snow or rain? - A matter of wet-bulb temperature, thesis, Uppsala Univ., Uppsala, Sweden, available at: http://www.geo. uu.se/luva/exarb/2003/Arvid_Olsen.pdf (last access: 22 August 2016), 2003.

Olson, W. S., Kummerow, C. D., Heymsfield, G. M., and Giglio, L.: A method for combined passive-active microwave retrievals of cloud and precipitation profiles, J. Appl. Meteorol., 35, 1763-1789, doi:10.1175/15200450(1996)035<1763:amfcpm>2.0.co;2, 1996. 
Pachauri, R. K.: Intergovernmental panel on climate change (IPCC): Keynote address, Environ. Sci. Pollut. Res., 9, 436-438, 2002.

Pagano, T. C., Wood, A. W., Ramos, M. H., Cloke, H. L., Pappenberger, F., Clark, M. P., Cranston, M., Kavetski, D., Mathevet, T., Sorooshian, S., and Verkade, J. S.: Challenges of Operational River Forecasting, J. Hydrometeorol., 15, 1692-1707, doi:10.1175/jhm-d-13-0188.1, 2014.

Parajka, J., Haas, P., Kirnbauer, R., Jansa, J., and Bloeschl, G.: Potential of time-lapse photography of snow for hydrological purposes at the small catchment scale, Hydrol. Proc., 26, 33273337, doi:10.1002/hyp.8389, 2012.

Park, H., Ryzhkov, A. V., Zrnic, D. S., and Kim, K.-E.: The Hydrometeor Classification Algorithm for the Polarimetric WSR88D: Description and Application to an MCS, Weather Forecast., 24, 730-748, doi:10.1175/2008waf2222205.1, 2009.

Pierce, D. W. and Cayan, D. R.: The uneven response of different snow measures to human-induced climate warming, J. Clim., 26, 4148-4167, 2013.

Pierce, D. W. and Cayan, D. R.: Downscaling humidity with localized constructed analogs (LOCA) over the conterminous united states, Clim. Dynam., 47, 411-431, 2016.

Pierce, D. W., Westerling, A. L., and Oyler, J.: Future humidity trends over the western United States in the CMIP5 global climate models and variable infiltration capacity hydrological modeling system, Hydrol. Earth Syst. Sci., 17, 1833-1850, doi:10.5194/hess-17-1833-2013, 2013.

Pipes, A. and Quick, M. C.: UBC watershed model users guide, Department of Civil Engineering, University of British Columbia, 1977.

Rajagopal, S. and Harpold, A.: Testing and Improving Temperature Thresholds for Snow and Rain Prediction in the Western United States, J. Am. Water Resour. Assoc., 2016.

Rasmussen, R., Baker, B., Kochendorfer, J., Meyers, T., Landolt, S., Fischer, A. P., Black, J., Thériault, J. M., Kucera, P., Gochis, D., Smith, C., Nitu, R., Hall, M., Ikeda, K., and Gutmann, E.: How Well Are We Measuring Snow: The NOAA/FAA/NCAR Winter Precipitation Test Bed, B. Am. Meteorol. Soc., 93, 811829, doi:10.1175/BAMS-D-11-00052.1, 2012.

Reisner, J., Rasmussen, R. M., and Bruintjes, R.: Explicit forecasting of supercooled liquid water in winter storms using the MM5 mesoscale model, Q. J. R. Meteor. Soc., 124, 1071-1107, 1998.

Rojas, R., Feyen, L., Dosio, A., and Bavera, D.: Improving panEuropean hydrological simulation of extreme events through statistical bias correction of RCM-driven climate simulations, Hydrol. Earth Syst. Sci., 15, 2599-2620, doi:10.5194/hess-15-25992011, 2011.

Safeeq, M., Mauger, G. S., Grant, G. E., Arismendi, I., Hamlet, A. F., and Lee, S. Y.: Comparing Large-Scale Hydrological Model Predictions with Observed Streamflow in the Pacific Northwest: Effects of Climate and Groundwater, J. Hydrometeorol., 15, 2501-2521, doi:10.1175/jhm-d-13-0198.1, 2014.

Sevruk, B.: Assessment of snowfall proportion in monthly precipitation in Switzerland, Zbornik meteoroloskih i Hidroloskih Radovav Beograd, 10, 315-318, 1984.

Shamir, E. and Georgakakos, K. P.: Distributed snow accumulation and ablation modeling in the American River basin, Adv. Water Resour., 29, 558-570, doi:10.1016/j.advwatres.2005.06.010, 2006.
Skamarock, W. C., Klemp, J. B., Dudhia, J., Gill, D. O., Barker, D. M., Duda, M. G., Huang, X.-Y., Wang, W., and Powers, J. G.: A description of the advanced research WRF version 3NCAR Tech. Note NCAR/TN-475+STR, 113, 65-83, 2008.

Skofronick-Jackson, G., Hudak, D., Petersen, W., Nesbitt, S. W., Chandrasekar, V., Durden, S., Gleicher, K. J., Huang, G.-J., Joe, P., Kollias, P., Reed, K. A., Schwaller, M. R., Stewart, R., Tanelli, S., Tokay, A., Wang, J. R., and Wolde, M.: Global Precipitation Measurement Cold Season Precipitation Experiment (GCPEX): For Measurement's Sake, Let It Snow, B. Am. Meteorol. Soc., 96, 1719-1741, doi:10.1175/BAMS-D-13-00262.1, 2015.

SNTHERM: Online Documentation, available at: http: //www.geo.utexas.edu/climate/Research/SNOWMIP/

SUPERSNOW2/rjordan.html, last access: 22 August 2016.

Stewart, R. E.: Precipitation Types in the Transition Region of Winter Storms, B. Am. Meteorol. Soc., 73, 287-296, 1992.

Stewart, R. E., Theriault, J. M., and Henson, W.: On the Characteristics of and Processes Producing Winter Precipitation Types near $0{ }^{\circ}$ C, B. Am. Meteorol. Soc., 96, 623-639, doi:10.1175/bams-d14-00032.1, 2015.

Tague, C. L. and Band, LE.: RHESSys: Regional Hydro-Ecologic Simulation System - An Object Oriented Approach to Spatially Distributed Modeling of Carbon, Water, and Nutrient Cycling, Earth Interact., 8, 1-42, 2004.

Tarboton, D., Jackson, T., Liu, J., Neale, C., Cooley, K., and McDonnell, J.: A Grid Based Distributed Hydrologic Model: Testing Against Data from Reynolds Creek Experimental Watershed, Preprints AMS Conf. Hydrol, 79-84, 1995.

Tarboton, D. G. and Luce, C. H.: Utah Energy Balance Snow Accumulation and Melt Model (UEB), available at: http://www.fs.fed.us/rm/boise/publications/watershed/rmrs_ 1996_tarbotond001.pdf, (last access: 22 August 2016), 1996,

Thériault, J. M. and Stewart, R. E.: On the effects of vertical air velocity on winter precipitation types, Nat. Hazards Earth Syst. Sci., 7, 231-242, doi:10.5194/nhess-7-231-2007, 2007.

Theriault, J. M. and Stewart, R. E.: A Parameterization of the Microphysical Processes Forming Many Types of Winter Precipitation, J. Atmos. Sci., 67, 1492-1508, doi:10.1175/2009jas3224.1, 2010.

Theriault, J. M., Stewart, R. E., and Henson, W.: On the Dependence of Winter Precipitation Types on Temperature, Precipitation Rate, and Associated Features, J. Appl. Meteorol. Clim., 49, 1429-1442, doi:10.1175/2010jamc2321.1, 2010.

Theriault, J. M., Stewart, R. E., and Henson, W.: Impacts of terminal velocity on the trajectory of winter precipitation types, Atmos. Res., 116, 116-129, doi:10.1016/j.atmosres.2012.03.008, 2012.

Thompson, E. J., Rutledge, S. A., Dolan, B., Chandrasekar, V., and Cheong, B. L.: A Dual-Polarization Radar Hydrometeor Classification Algorithm for Winter Precipitation, J. Atmos. Ocean. Tech., 31, 1457-1481, doi:10.1175/jtech-d-13-00119.1, 2014.

Thompson, G., Rasmussen, R. M., and Manning, K.: Explicit forecasts of winter precipitation using an improved bulk microphysics scheme, Part I: Description and sensitivity analysis, Mon. Weather Rev., 132, 519-542, 2004.

Thompson, G., Field, P. R., Rasmussen, R. M., and Hall, W. D.: Explicit forecasts of winter precipitation using an improved bulk microphysics scheme, Part II: Implementation of a new snow parameterization, Mon. Weather Rev., 136, 5095-5115, 2008. 
Todini, E.: The ARNO Rainfall-runoff model, J. Hydrol., 175, 339382, 1996.

Tung, C.-P. and Haith, D. A.: Global-warming effects on New York streamflows, J. Water Resour. Plann. Manage., 121, 216-225, 1995.

US Army Corps of Engineers: Summary Report of the Snow Investigation Hydrological Practices, 3rd Edn., Chapter 2, North Pacific Division, Portland, Oregon, 54-56, 1956.

Verseghy, D.: CLASS-The Canadian Land Surface Scheme, Version 3.4, Technical Documentation, Version 1.1, Environment Canada, available at: http://www.usask.ca/ip3/download/ CLASS_v3_4_Documentation_v1_1.pdf, (last access: $22 \mathrm{Au}-$ gust 2016), 2009.

VIC Documentation: Development and Maintenance Documentation, available at: https://vic.readthedocs.io/en/develop/, last access: 22 August 2016.

Wang, R., Kumar, M., and Marks, D.: Anomalous trend in soil evaporation in a semi-arid, snow-dominated watershed, Adv. Water Resour., 57, 32-40, 2013.

Wang, R., Kumar, M., and Link, T. E.: Potential trends in snowmelt generated peak streamflows in a warming climate, Geophys. Res. Lett. 43, 5052-5059, doi:10.1002/2016GL068935, 2016.

Wen, L., Nagabhatla, N., Lu, S., and Wang, S.-Y.: Impact of rain snow threshold temperature on snow depth simulation in land surface and regional atmospheric models, Adv. Atmos. Sci., 30, 1449-1460, doi:10.1007/s00376-012-2192-7, 2013.

White, A. B., Gottas, D. J., Strem, E. T., Ralph, F. M., and Neiman, P. J.: An automated brightband height detection algorithm for use with Doppler radar spectral moments, J. Atmos. Ocean. Tech., 19, 687-697, 2002.

White, A. B., Gottas, D. J., Henkel, A. F., Neiman, P. J., Ralph, F. M., and Gutman, S. I.: Developing a Performance Measure for Snow-Level Forecasts, J. Hydrometeorol., 11, 739-753, doi:10.1175/2009jhm1181.1, 2010.

Whiteman, C. D., Bian, X., and Zhong, S.: Wintertime evolution of the temperature inversion in the colorado plateau basin, J. Appl. Meteorol., 38, 1103-1117, 1999.
Wigmosta, M. S., Vail, L. W., and Lettenmaier, D. P.: A distributed hydrology-vegetation model for complex terrain, Water Resour. Res., 30, 1665-1679, 1994.

Wilheit, T. T., Chang, A. T. C., King, J. L., Rodgers, E. B., Nieman, R. A., Krupp, B. M., Milman, A. S., Stratigos, J. S., and Siddalingaiah, H.: Microwave radiometric observation nea 19.35, 92 and $183 \mathrm{GHz}$ of precipitation in tropical storm Cora, J. Appl. Meteorol., 21, 1137-1145, 1982.

Wood, A. W., Leung, L. R., Sridhar, V., and Lettenmaier, D.: Hydrologic implications of dynamical and statistical approaches to downscaling climate model outputs, Climatic Change, 62, 189216, 2004.

Wood, N., L'Ecuyer, T. S., Vane, D., Stephens, G., and Partain, P.: Level $2 \mathrm{C}$ snow profile process description and interface control document, 2013.

Yamazaki, T.: A One-dimensional Land Surface Model Adaptable to Intensely Cold Regions and its Applications in Eastern Siberia, J. Meteorol. Soc. Jap., 79, 1107-1118, 2001.

Yang, Z. L., Dickinson, R. E., Robock, A., and Vinniko, K. Y.: Validation of the Snow Submodel of the Biosphere-Atmosphere Transfer Scheme with Russian Snow Cover and Meteorological Observational Data, J. Clim., 10, 353-373, 1997.

Yarnell, S. M., Viers, J. H., and Mount, J. F.: Ecology and Management of the Spring Snowmelt Recession, Bioscience, 60, 114 127, doi:10.1525/bio.2010.60.2.6, 2010.

Ye, H., Cohen, J., and Rawlins, M.: Discrimination of Solid from Liquid Precipitation over Northern Eurasia Using Surface Atmospheric Conditions, J. Hydrometeorol., 14, 1345-1355, doi:10.1175/jhm-d-12-0164.1, 2013.

Yucel, I., Onen, A., Yilmaz, K. K., and Gochis, D. J.: Calibration and evaluation of a flood forecasting sytem: Utility of numerical weather prediction model, data assimilate, and satellite-based rainfall, J. Hydrol., 523, 49-66, doi:10.1016/j.hydrol.2015.01.042, 2015.

Zängl, G.: Interaction between dynamics and cloud microphysics in orographic precipitation enhancement: A high-resolution modeling study of two North Alpine heavy-precipitation events, Mon. Weather Rev., 135, 2817-2840, 2007.

Zanotti, F., Endrizzi, S., Bertoldi, G., and Rigon, R.: The GEOTOP snow module, Hydro. Proc., 18, 3667-3679, doi:10.1002/hyp.5794, 2004. 